\title{
Synaptic Vesicle Recycling and the Endolysosomal System: A Reappraisal of Form and Function
}

\author{
Daniela Ivanova1,2,3* and Michael A. Cousin ${ }^{1,2,3 *}$ \\ ${ }^{1}$ Centre for Discovery Brain Sciences, University of Edinburgh, Edinburgh, United Kingdom, ${ }^{2}$ Muir Maxwell Epilepsy Centre, \\ University of Edinburgh, Edinburgh, United Kingdom, ${ }^{3}$ Simons Initiative for the Developing Brain, University of Edinburgh, \\ Edinburgh, United Kingdom
}

OPEN ACCESS

Edited by:

Lucia Tabares,

Seville University, Spain

Reviewed by:

Rafael Fernández-Chacón, Institute of Biomedicine of Seville

(CSIC), Spain

Cláudia Guimas Almeida,

New University of Lisbon, Portugal

*Correspondence:

Daniela Ivanova

D.Ivanova@ed.ac.uk

Michael A. Cousin

M.Cousin@ed.ac.uk

Received: 30 November 2021 Accepted: 03 February 2022

Published: 25 February 2022

Citation:

Ivanova D and Cousin MA (2022)

Synaptic Vesicle Recycling and the Endolysosomal System:

A Reappraisal of Form and Function. Front. Synaptic Neurosci. 14:826098.

doi: 10.3389/fnsyn.2022.826098
The endolysosomal system is present in all cell types. Within these cells, it performs a series of essential roles, such as trafficking and sorting of membrane cargo, intracellular signaling, control of metabolism and degradation. A specific compartment within central neurons, called the presynapse, mediates inter-neuronal communication via the fusion of neurotransmitter-containing synaptic vesicles (SVs). The localized recycling of SVs and their organization into functional pools is widely assumed to be a discrete mechanism, that only intersects with the endolysosomal system at specific points. However, evidence is emerging that molecules essential for endolysosomal function also have key roles within the SV life cycle, suggesting that they form a continuum rather than being isolated processes. In this review, we summarize the evidence for key endolysosomal molecules in SV recycling and propose an alternative model for membrane trafficking at the presynapse. This includes the hypotheses that endolysosomal intermediates represent specific functional SV pools, that sorting of cargo to SVs is mediated via the endolysosomal system and that manipulation of this process can result in both plastic changes to neurotransmitter release and pathophysiology via neurodegeneration.

Keywords: vesicle, endocytosis, endosome, trafficking, presynapse, lysosome

\section{INTRODUCTION}

Compartmentalization in eukaryotic cells enables efficient spatiotemporal control of multiple parallel cellular processes by concentrating the required factors in confined microenvironments that provide the best conditions for these processes to proceed. The endomembrane system, which includes the majority of membrane-bound organelles and the plasma membrane, plays a key role in segregating the intracellular environment into functional hubs. However, organelles do not operate as autonomous modules and without a regulated exchange of molecules between the compartments, their overall function would soon be compromised. Therefore, all membranebound organelles engage in extensive communication that coordinates their functions and enables long-term maintenance of cellular homeostasis.

\section{The Endolysosomal System}

The endolysosomal system is a dynamic network of intracellular membranous organelles, where the endocytic, biosynthetic, and degradative pathways intersect (Maxfield and McGraw, 2004; Grant and Donaldson, 2009). This collection of organelles is a key sorting station distributing cargo to different membrane domains, a signaling hub regulating cellular metabolism and an intermediate to degradation (Klumperman and Raposo, 2014; Naslavsky and Caplan, 2018). The endolysosomal 
system has been extensively studied in non-neuronal cells, however, in neurons its characteristics remain relatively ambiguous and poorly defined (Andres-Alonso et al., 2021; Kuijpers et al., 2021a). In non-neuronal cells, the highly heterogeneous collection of organelles which constitutes the endolysosomal system is generally classified into several compartments, including early endosome (EE), recycling endosome (RE), late endosome (LE), and lysosome (Maxfield and McGraw, 2004; Klumperman and Raposo, 2014; Naslavsky and Caplan, 2018). It is still a matter of debate whether these heterogeneous compartments with overlapping, but also unique, set of proteins are distinct organelles or a series of structures that undergo maturation and "evolve" from each other.

The EE is a major station for sorting of cargo previously internalized by endocytosis. Some cargos are recycled via a rapid recycling pathway directly from $\mathrm{EE}$, whereas others are trafficked to specialized RE, or endocytic recycling compartment, which is often but not always clustered in the perinuclear region, beside the microtubule-organizing center of the cell (Grant and Donaldson, 2009; Naslavsky and Caplan, 2018). In contrast to EEs, from which cargo can be recycled directly to the plasma membrane, the RE is involved in the "slow" recycling of internalized cargo (Li and DiFiglia, 2012). LEs are a group of organelles structurally and functionally related to lysosomes. Like lysosomes, LEs play a key role in protein degradation and are also essential components of the autophagy pathway (Scott et al., 2014). In addition, they are required for nutrient sensing and transport of cholesterol and other lipids to other membranous organelles in the cell (Scott et al., 2014). Lysosomes are the main waste disposal system of the cell, degrading materials delivered by autophagy or endocytosis into their basic building blocks. In addition, they participate in multiple other cellular processes, including regulation of metabolic signaling, gene expression, plasma membrane repair and lipid sensing and trafficking (Luzio et al., 2007; Saftig and Klumperman, 2009; Ballabio and Bonifacino, 2020).

\section{Synaptic Vesicle Recycling}

The recycling of neurotransmitter-containing synaptic vesicles (SVs) at nerve terminals is one of the most extensively studied cellular pathways in central neurons. This process is essential for the neuronal communication, with even small perturbations resulting in a series of neurodevelopmental, neurodegenerative disorders or death (Bonnycastle et al., 2021; Overhoff et al., 2021). SVs are small $50 \mathrm{~nm}$ organelles that accumulate neurotransmitter via specialized transporters that are coupled to an intraluminal protonmotive force generated by V-type ATPases on the SV membrane. Neurotransmitter-filled SVs undergo a series of molecular events before they are triggered to fuse with the presynaptic plasma membrane during synaptic stimulation. These include a physical attachment to the plasma membrane (docking), a transition to fusion competency (priming), and calcium-triggered fusion (exocytosis) (Brunger et al., 2018; Rizo, 2018). After fusion, SV proteins and membrane are retrieved via endocytosis that is triggered by neuronal activity and proceeds at different speeds and locations in the nerve terminal (Chanaday et al., 2019).
Within central nerve terminals, three pools of SVs have been described based on their availability for release, the readily releasable pool (RRP), recycling pool and resting/reserve pool. A fourth pool, termed "super pool," that is shared between neighboring en passant boutons and trafficked along the axon, has also been reported (Staras et al., 2010; Herzog et al., 2011; Zhang et al., 2019). Furthermore, several studies have suggested that separate SV pools drive different forms of neurotransmitter release (e.g., spontaneous, evoked synchronous and evoked asynchronous release) (Chanaday and Kavalali, 2018). However, this concept remains controversial, and has been refuted by others (Hua et al., 2010). This controversy may in large part be due to the fact that the majority of current studies focus on SV recycling as an isolated process. Our understanding of how the SV cycle integrates in the general endomembrane system in neurons and the functional implications of its communication with other membrane trafficking pathways, remains limited. Specifically, very little is known about the biogenesis and maintenance of the SV cluster across the lifespan of the neuron. Furthermore, fundamental questions about the mechanisms that mediate turnover of SV components also remain unanswered. These questions cannot be adequately addressed unless a more holistic understanding of the SV cycle and its place in the general endomembrane system in neurons is developed.

However, this important question is difficult to address, since there are only a few distinctive molecular markers that define EE and especially RE, which has made the characterization of their cellular localization and function a challenging endeavor. Defining EE and RE, their function in neuronal cells, and in particular in synaptic terminals, has proven to be a monumental task, partly due to the reductionist approach to SV recycling largely adopted by the field. Although it has its place, the fixation on detail often leads to inability to "see the wood for the trees."

There is accumulating evidence to suggest that SV recycling and axonal endolysosomal trafficking are both structurally and functionally linked. However, the extent to which they are entangled is difficult to envision because of the lack of a conceptual framework that juxtaposes the two pathways in synaptic terminals. In this review, we propose an alternative interpretation of SV recycling by proposing that the SV pool is an integral part of the endolysosomal system in neurons, with equivalents of EE, RE, LE, and lysosomes functioning in concert at the presynapse, and supporting not only synaptic transmission, but the overall health of the neuron. In doing so, we will discuss the current evidence for crosstalk and potential overlap between the endolysosomal system and the SV recycling pathway, by examining the role of endolysosomal molecules in SV recycling which form the foundation of a series of testable hypotheses for future studies.

\section{ENDOCYTOSIS AND EARLY ENDOSOMES}

\section{Endocytosis}

The first stage of the endolysosomal pathway is endocytosis. Due to its capacity to regulate the surface expression and 
internalization of membrane and soluble molecules, endocytosis is a fundamental cellular mechanism that regulates a multitude of cellular processes, including uptake of nutrients, cell signaling, establishment of cellular polarity, cell motility, and neurotransmission (Conner and Schmid, 2003; Doherty and McMahon, 2009). Although clathrin-dependent endocytosis is the most studied and best characterized endocytosis pathway, owing to their high capacity, clathrin-independent mechanisms are now recognized as the main route for internalization of cargo, responsible for the majority $(\sim 70 \%)$ of membrane and fluid uptake into the cell (Howes et al., 2010; Renard and Boucrot, 2021). Neurons and synaptic terminals are no exception from this rule. There is accumulating evidence, that clathrin-independent, bulk membrane retrieval is also the dominant pathway for membrane retrieval in central nerve terminals across a range of stimuli, but particularly during intense neuronal activity (Clayton et al., 2008; Kononenko et al., 2014). During this endocytic process, known as activity-dependent bulk endocytosis (ADBE), endosomes are formed directly from the plasma membrane (bulk endosomes) with SVs subsequently regenerated from these compartments (Kokotos and Cousin, 2015). Clathrin still performs an essential role in the reformation of SVs and selection of SV cargo, however, there is an emerging consensus that this occurs at the level of the internalized endosome, rather than at the plasma membrane (Watanabe et al., 2014; Kononenko and Haucke, 2015). The formation of endosomes can occur at different timescale from tens of milliseconds (e.g., the recently reported ultrafast endocytosis) to tens of seconds, depending on the strength of the stimulus input (Watanabe et al., 2013, 2018; Soykan et al., 2017). The lack of clathrin dependence of SV endocytosis is particularly pertinent in experiments performed at physiological temperatures (Kononenko et al., 2014; Watanabe et al., 2014; Delvendahl et al., 2016). In these conditions, the relatively slow assembly of the clathrin coat means that clathrinmediated budding events that originate on the plasma membrane are finalized on the endosome, due to the rapid invagination of these structures. Several other forms of endocytosis have been proposed to operate at the presynapse: e.g., clathrin-independent endocytosis (CIE) (Soykan et al., 2016), clathrin-independent and calcium-independent endocytosis (Orlando et al., 2019) and "kiss-and-run" (Stevens and Williams, 2000; He et al., 2006; Zhang et al., 2009). However, they either represent the same process of clathrin-independent bulk membrane retrieval under a different name (CIE) or their existence and contribution to presynaptic function at typical small central nerve terminals remains a matter of debate ("kiss-and-run") (Granseth et al., 2006; LoGiudice and Matthews, 2006; Wu et al., 2014).

\section{Early Endosome Function}

Classical EEs in non-neuronal cells are marked by a series of molecules with specific functional roles. For example, they typically contain a high concentration of the lipid phosphatidylinositol 3-phosphate (PI(3)P), generated by the PI3kinase VPS34 (Grant and Donaldson, 2009). VPS34 is a class III phosphatidylinositol 3-kinase that uses phosphatidylinositol as a substrate to generate $\mathrm{PI}(3) \mathrm{P}$. Previous studies have revealed an important role for VPS34 in EE-sorting and autophagy
(Dall'Armi et al., 2013; Raiborg et al., 2013). Accumulation of $\mathrm{PI}(3) \mathrm{P}$ is required for the recruitment of proteins to EEs that contain a FYVE PI(3)P-binding domain, such as early endosomal antigen 1 (EEA1) and rabenosyn-5. EEA1 functions as a tethering molecule that together with the endosomal soluble N-ethylmaleimide attachment protein receptor (SNARE) proteins controls the maturation of $\mathrm{EE}$ and their homotypic fusion (Maxfield and McGraw, 2004). SNARE proteins are classified as either Q- or R-SNAREs dependent on the presence of highly conserved glutamine or arginine residues at the center of their SNARE motif that drives fusion (Jahn and Scheller, 2006). Typically, R-SNAREs reside on the vesicular membrane whereas Q-SNAREs reside on target membranes. Rabenosyn5 is also required for early endosomal fusion. In addition, rabenosyn-5, associates with another important class of EEassociated proteins, the dynamin-like EHD (Eps15 Homology Domain) ATPases, to regulate the transport of cargo from EEs to REs (Naslavsky and Caplan, 2011).

Another layer of identity for the organelles in the endolysosomal system is provided by the small Rab GTPases. They are considered "deciphers of organelle identity" and serve as platforms for recruitment of specific molecular machineries that confer unique functional characteristics to the particular organelles they bind to Stenmark (2009). The Rab GTPases that typically associate with EEs include Rab4, Rab5, Rab10, Rab14, Rab21, and Rab22 (Stenmark, 2009). It has been suggested that $\mathrm{Rab}$ proteins on EE cluster in district membrane microdomains. However, the precise mechanisms by which proteins are clustered into these domains remain poorly understood.

The SNARE-based vesicle fusion system is key for endosomal fusion and transport. After cargo proteins have been sorted into EE subdomains, a process of budding and fission of tubulovesicular structures occurs and the newly formed vesicles are trafficked to their target organelle (Grant and Donaldson, 2009). Some of the most important early endosomal SNAREs involved in homotypic and heterotypic endosomal fusion include VAMP4, syntaxin 6, syntaxin 12 (called syntaxin 13 in rat), and Vtila. The R-SNARE VAMP4 and the Q-SNAREs syntaxin 6, syntaxin 12, and Vtila predominantly localize at the trans-Golgi network (TGN), but are also found at the plasma membrane, EE and RE, with VAMP4 and syntaxin 6 also present on lysosomerelated secretory organelles (Maxfield and McGraw, 2004). All four are implicated in the homotypic fusion of EEs by forming a SNARE complex with each other. In addition, VAMP4 and Vtila have a central role in the retrograde endosome-to- TGN transport (Johannes and Popoff, 2008; Hirata et al., 2015). This pathway is important for recycling of molecules to the TGN, that in turn enable efficient anterograde transport of transmembrane proteins. Both VAMP4 and Vtila are involved in maintaining the ribbon structure of the TGN (Shitara et al., 2013).

\section{Early Endosome and Synaptic Vesicle Recycling}

When considering the role of EEs in SV recycling, a key question to address is - are any of the molecules mentioned above implicated in this process? Many of the EE markers outlined 
above are enriched in nerve terminals and some have links to SV recycling.

In neuronal axons, PI3-kinase activity is important for long-range trafficking, actin-based membrane ruffling and bulk membrane retrieval in growth cones, all of which support axonal outgrowth during neuronal development (Bonanomi et al., 2008; Zhou et al., 2013; Lorenzo et al., 2014). In mature presynaptic boutons, PI3-kinase activity supports actin remodeling and a signaling cascade linked to ADBE (Holt et al., 2003; NicholsonFish et al., 2016). Furthermore, inhibition of PI3-kinase activity stalls SV recycling and results in the appearance of numerous cisternae in synaptic terminals (Rizzoli and Betz, 2002; Richards et al., 2004). Presynaptic PI3-kinase activity is coupled to membrane depolarization and calcium influx, in a similar manner to SV recycling (Nicholson-Fish et al., 2016). PI3kinase activity is also associated with the SV protein synapsin and it is required for optimal replenishment of the RRP from the reserve pool (Cousin et al., 2003). However it should be noted that the PI3-kinase activity associated with synapsin was from Class I PI3-kinases [which generate $\mathrm{PI}(3,4,5) \mathrm{P}_{3}$ ], whereas the activity required for classical EE function is via Class III [which generate PI(3)P]. Although, FYVE-domain-containing proteins, such as EEA1 and rabenosyn-5 were reported to show a polarized distribution to the somato-dendritic domain, they have been detected in axons (Selak et al., 2004; Ackermann et al., 2019; Goto-Silva et al., 2019). However, more research is warranted to shed light on their exact presynaptic function. Finally, biochemical studies examining endosomes purified from AP1 (adaptor protein 1) $\sigma$ knockout mice suggest that VPS34 is required for the maturation of $\mathrm{LE}$ and lysosomes (multivesicular bodies) in axons via a mechanism which involves sorting at presynaptic endosomes mediated by ADP-ribosylation factor GTPase activating protein 1 and Rab5 GDP/GTP exchange factor (Candiello et al., 2016). This implies that, in presynaptic terminals, PI3-kinase activity may be at the core of a mechanism operating at the presynaptic endosomes which coordinates both generation of functional SVs and degradative pathways.

More than 11 distinct Rabs, including most of the early endosomal Rabs, were detected on the surface of highly purified SV membranes (Pavlos et al., 2010; Pavlos and Jahn, 2011). The best characterized early endosomal Rab, Rab5, is present in a subpopulation of SVs at the presynapse, with its manipulation resulting in alterations to SV recycling. For example, overexpression of Rab5 reduced the size of the recycling SV pool in hippocampal neurons by $50 \%$ (Star et al., 2005), whereas dominant negative Rab5 expression impaired SV recycling (Shimizu et al., 2003; Wucherpfennig et al., 2003). Furthermore, wild-type and constitutively active Rab5 rescued defective SV endocytosis produced by knockdown of the protein kinase leucine rich repeat kinase 2 (LRRK2) (Shin et al., 2008). Another early endosome Rab, Rab4, traffics bidirectionally within the axon and is enriched at synapses, with a reduction in its anterograde trafficking resulting in aberrant synaptic morphology (Dey et al., 2017; White et al., 2020). Therefore, classical EE Rabs are present at the presynapse and modulate the SV life cycle, providing further evidence of crosstalk and functional integration.
A number of endosomal SNAREs are implicated in SV recycling. For example, a series of early endosome Q-SNARE proteins (Vtila, syntaxin-6 and syntaxin-13) visit the presynaptic plasma membrane during brief stimulation or baseline activity, suggesting that endosomal SNAREs were present on SVs (Hoopmann et al., 2010; Ramirez et al., 2012). Vtila resides on SVs that recycle at rest and sustain spontaneous neurotransmission (Ramirez et al., 2012). More recently, Vtila (and Vti1b) were implicated in regulation of SV- and dense-core vesicle fusion at the presynapse by modulating secretory cargo sorting at the TGN (Emperador-Melero et al., 2018). The endosomal R-SNARE VAMP4, is present on highly purified SVs (Takamori et al., 2006), however, it does not readily visit the cell surface during neuronal activity (Raingo et al., 2012; Nicholson-Fish et al., 2015; Ivanova et al., 2021). VAMP4 has been proposed to control discrete forms of neurotransmission (Raingo et al., 2012; Lin et al., 2020), however, a more global role has recently been identified. This role is of a negative regulator of SV release probability $(\mathrm{Pr})$, with VAMP4 levels on SVs controlled via both $\mathrm{ADBE}$ and downstream endolysosomal processing (Ivanova et al., 2021). Altogether, this highlights EE proteins as an integral component and a key modulator of SV recycling.

\section{Retromer Function}

The retromer protein complex is a critical component of the machinery mediating sorting and trafficking from EE (Seaman, 2012; Burd and Cullen, 2014). It was first characterized in yeast as a complex involved in the retrograde trafficking of membrane proteins, from peripheral endosomes to the TGN (Seaman et al., 1998), but a role in the trafficking of cargo to the plasma membrane has also been described (Small and Petsko, 2015). It consists of two main parts, the cargo-selection complex (CSC) and the tubulation module. In mammals, the two modules are not tightly coupled and can function independently. The CSC is composed of three proteins VPS26, VPS29, and VPS35, whereas the tubulation module is a heterodimer of the BAR (Bin, Amphiphysin, Rvs)-containing sorting nexins SNX1/SNX2 and SNX5/SNX6 (Seaman, 2012; Gallon and Cullen, 2015).

It is assumed that the GTPase activity of dynamin is important for scission of retromer-containing vesicles at EEs (Naslavsky and Caplan, 2018). Association of EHD ATPases and several of their endocytic interaction partners (e.g., syndapin and MICALlike protein 1) with retromer in domains where vesicles are being generated at EE has also been shown (Gokool et al., 2007; Naslavsky and Caplan, 2011; McKenzie et al., 2012). It was suggested that both motor pulling by different fission complexes and the force generated by the WASH-mediated nucleation of actin, are important for the budding of vesicles from EE (Derivery et al., 2009; Jia et al., 2012; Capitani and Baldari, 2021).

\section{Retromer and Synaptic Vesicle Recycling}

The retromer complex and EHD are ubiquitously expressed in the nervous system, and they are both enriched in the presynaptic compartment (Jakobsson et al., 2011; Li and DiFiglia, 2012; Inoshita et al., 2017). Retromer function is essential for neuronal development and constitutive knockout of VPS35 is embryonically lethal, whereas heterozygous knockout hinders the 
development of both axons and dendrites (Wen et al., 2011; Tian et al., 2015). Investigation of the effect of VPS35 knockdown on presynaptic function in mouse hippocampal neurons, failed to detect any deficits in SV exo- and endocytosis (Vazquez-Sanchez et al., 2018). However, deletion of VPS35 in Drosophila larvae led to a reduced number and altered morphology of SVs in motor terminals which was accompanied by enhanced rundown of synaptic transmission, suggesting a functional role of retromer in SV recycling (Inoshita et al., 2017). However, given the apparent discrepancy between these two model systems, further studies are required to adjudicate on the precise function of retromer in the SV cycle. Interestingly, retromer dysfunction is involved in the pathoetiology of neurodegenerative diseases such as Alzheimer's and Parkinson's disease, a common early hallmark of which is disruption of presynaptic function (Small and Petsko, 2015).

EHD1 is also linked to SV recycling. In addition to a potential negative regulation of SV exocytosis (Wei et al., 2010), EHD1 is required for clathrin-independent endocytosis. For example, its removal at the lamprey giant reticulospinal synapse, blocks SV endocytosis due to defective dynamin-induced membrane tubulation (Jakobsson et al., 2011). Furthermore EHDs associate with syndapins (Braun et al., 2005), F-BAR-proteins with pivotal role in $\mathrm{ADBE}$ and SV reformation at bulk endosomes (Clayton et al., 2009; Koch D. et al., 2011; Quan et al., 2012; Cheung and Cousin, 2019).

\section{RECYCLING ENDOSOME}

\section{Recycling Endosome Function}

An alternative mechanism for trafficking of cargo from the EE to the RE involves a process of organelle maturation. This mechanism does not require generation of vesicles from the EE and their fusion with the RE, but the entire EE changes its identity and matures to RE by acquiring a set of characteristic proteins, such as Rab11, Rab35, cellubrevin (VAMP3), ADP-ribosylation factor 6 (Arf6), and EHD1 (Grant and Donaldson, 2009). There are no typical resident proteins that define REs. Thus, rather than a "stable" compartment that receives cargo from the EE, the RE can be viewed as the residual organelle that remains from the EE after cargo sorting to LEs. As stated above, the major function of REs is as a trafficking intermediate for cargo proteins that normally undergo recycling to the plasma membrane. In most cell types, REs are a collection of tubule-vesicular structures of approximately $60 \mathrm{~nm}$ in diameter that localize to the perinuclear region in the vicinity of microtubule-organizing center ( $\mathrm{Li}$ and DiFiglia, 2012; Goldenring, 2015). However, the perinuclear distribution of REs does not seem to be essential for their function and in some cells, REs are dispersed throughout the cytoplasm (Joensuu et al., 2017; Naslavsky and Caplan, 2018).

Rab11 has been broadly accepted as the main regulator of slow recycling through REs and its function is implicated in the recycling of a vast array of membrane proteins ranging from cell adhesion molecules to membrane receptors and ion channels (Li and DiFiglia, 2012). How Rab11 exerts its function in the regulation of RE trafficking is not well established, however. One prediction is that Rab11 controls the formation of vesicles from
RE by recruiting EHD1 and its interactors, such as syndapin2, that collectively promote fission of cargo carriers (Naslavsky and Caplan, 2011; Li and DiFiglia, 2012). RE have been reported to also function as a sorting intermediate for proteins synthesized at the TGN that are destined for secretion (Murray et al., 2005). The integrity of the R-SNARE VAMP3/cellubrevin and Rab11 functions were shown to be crucial for the RE-mediated secretion of newly synthesized proteins (Murray et al., 2005).

The GTPase Arf6 is another molecular marker regulating the endocytic trafficking through RE whose function is essential in all cell types for multiple cellular events, including regulation of cell shape, cytokinesis, cell migration, and tumor cell invasion (Sheehan and Waites, 2019). Rab35 is also required for recycling previously endocytosed cargo to the plasma membrane as part of the RE system (Klinkert and Echard, 2016). Intricate reciprocal antagonistic processes regulate the active/inactive state of both Rab35 and Arf6, suggesting these GTPases are key effectors in RE function (Sheehan and Waites, 2019).

As stated above, a systematic investigation of $\mathrm{RE}$ has been challenging because of the difficulties identifying unique molecular tags for this organelle. The challenge to decipher the molecular basis of the RE points to the possibility that REs are not a single organelle but a constellation of interconnected, semiautonomous organelles that collectively coordinate the trafficking of specific cargos to the plasma membrane. Therefore, it is easy to envisage that specializations of this system exist within different cell types and cellular compartments and account for regulation of the trafficking of compartment-specific cargo molecules.

\section{Recycling Endosomes and Synaptic Vesicle Recycling}

There is accumulating evidence that key components of the RE machinery, such as Rab35, Arf6, and their effectors, perform important roles in both SV recycling and processing of SV cargo. For example, Drosophila hypomorphic mutants for the Rab35 GAP, skywalker, display a large increase in presynaptic endosomes during neuronal activity (Uytterhoeven et al., 2011). Constitutively active Rab5, 23, and 35 mutants all phenocopied this defect, suggesting a key role of EE/RE effectors in SV recycling. The human skywalker orthologue TBC1 Domain Family Member 24 (TBC1D24) appears to perform a parallel role in mammalian nerve terminals. For example, its depletion caused defective growth cone endocytosis and axonal initial segment maturation resulting in altered action potential firing (Aprile et al., 2019). In addition, neurons from mice haploinsufficient for TBC1D24 displayed dysfunctional SV endocytosis, with a threefold increase in the volume of presynaptic endosomes, consistent with the phenotype in Drosophila sky mutants (Finelli et al., 2019). Interestingly, similar SV recycling phenotypes are observed in neurons in which endogenous Arf6 was depleted (Tagliatti et al., 2016). Since TBC1D24 regulates the activation state of Arf6 (Falace et al., 2014; Aprile et al., 2019), this suggests that Arf6 represses trafficking via endosomal SV recycling routes, whereas Rab35 promotes endosomal recycling. In support, depletion of the Rab35 guanine nucleotide exchange factor connecdenn in primary neuronal culture greatly reduces 
endocytosis during strong stimulation (Allaire et al., 2006). In addition, the Rab35/Arf6 system controls the degradation of specific SV cargos. For example, increased endosomal flux via skywalker increases the functional size of the RRP, due to rejuvenation of specific SV cargo components (Uytterhoeven et al., 2011). Furthermore, interference with this endosomal sorting route restored RRP size (Fernandes et al., 2014).

Rab11 is associated with both REs and LE/lysosomes, and has also been linked to SV recycling, mainly in model organisms. In these studies, Rab11 performs a facilitatory role. For example, its knockdown in C. elegans resulted in SV endocytosis defects (Han et al., 2017), whereas its expression in either a Drosophila model of Huntington's Disease or Vps35 null flies restored the SV size to control levels (Steinert et al., 2012; Inoshita et al., 2017). In mammalian neurons, overexpression of constitutively active Rab11 mutants facilitated SV endocytosis (Kokotos et al., 2018). Therefore, molecules essential for RE function are also required for optimal SV endocytosis and cargo trafficking at the presynapse. This suggests that REs are fully integrated into the SV recycling system and even that some SVs that undergo spontaneous and evoked fusion may in fact be considered as a type of REs.

\section{LATE ENDOSOMES/LYSOSOMES}

\section{Late Endosome/Lysosome Function}

Molecular discrimination between LEs and lysosomes is challenging because of the absence of selective molecular markers between these organelles. However, these compartments have different origins. LEs are formed from dynamic EEs as endocytic carrier vesicles, which undergo a conversion during which the small GTPase Rab5 is exchanged for Rab7 (Stoorvogel et al., 1991; Rink et al., 2005). Similar to other types of endosomes, they are a heterogeneous group of organelles. One specific kind of LE contains lumenal vesicles and are often described as multi-vesicular bodies (MVB) (Piper and Katzmann, 2007). The sorting of ubiquitinated membrane proteins into intralumenal vesicles and the mechanism by which MVB are formed, which typically involves the function of the ESCRT (endosomal sorting complexes required for transport) complexes, has been extensively discussed elsewhere (Hurley, 2008, 2015; Wollert and Hurley, 2010; Vietri et al., 2020).

Lysosomes on the other hand, are the terminal degradative compartment for cargo internalized through endocytosis and intracellular cargo segregated during autophagy. Lysosomes are formed from the TGN, in a process during which lysosomal transmembrane proteins are delivered directly to the lysosome, whereas newly synthesized acid hydrolases are transported to the lysosome through an endosomal intermediate (Saftig and Klumperman, 2009). The indirect route allows TGN recycling of the mannose-6-phosphate receptor, which binds to the mannose-6-phosphate tag on the acid hydrolases and sorts them to the lysosome. Lysosomes are, essentially, storage containers for degradative enzymes, which periodically fuse with late endosomes, autophagosomes, or other hybrid organelles (amphisomes), to form a compartment in which degradation occurs (Ballabio and Bonifacino, 2020). The regeneration of functional lysosomes from these compartments after degradation is another route for maintaining the lysosomal pool and cellular homeostasis (Yang and Wang, 2021). However, the function of lysosomes is not restricted to degradation of cellular components: they can also undergo regulated exocytosis in response to an increase in the intracellular calcium concentration (Martinez et al., 2000). Lysosome exocytosis is believed to supply extra membrane for plasma membrane repair (Reddy et al., 2001), which is an essential homeostatic mechanism that prevents cell death and progression of multiple diseases (Zhen et al., 2021).

Similar to other fusion events, fusion of lysosomes or late endosomes with the plasma membrane is a sequential process that proceeds through different stages: tethering, formation of a trans-SNARE complex and fusion (Luzio et al., 2007). Organelle tethering is a prerequisite step for fusion, during which membrane organelles form links with each other. The composition of the tethers responsible for LE-lysosome fusion has not been completely established, but homotypic fusion and protein sorting complex, which is recruited by Rab7, is likely one of the components (Fernandes et al., 2014). Following tethering, the formation of a SNARE complex bridges across the two membranes and enables fusion. Compelling evidence exists that the Q-SNAREs syntaxin-7, syntaxin-8, and Vtilb are essential for both, homotypic late endosome fusion and heterotypic late endosome-lysosome fusion, whereas the R-SNARE VAMP7 is specifically required for late endosome-lysosome fusion (Luzio et al., 2010). VAMP7 also mediates fusion of lysosomes with the plasma membrane (Rao et al., 2004). The N-terminal longin domain of VAMP7 is a critical regulatory site for its endosomal sorting. The kinetics and the extent of the calciumdependent fusion of lysosomes with the plasma membrane are regulated by the calcium sensor synaptotagmin-7 (Syt7) (Martinez et al., 2000).

\section{Late Endosome/Lysosomes and Synaptic Vesicle Recycling}

In neurons, LEs formed at the synapse undergo progressive acidification and further maturation toward a lysosomal identity during their retrograde transport to the cell body (Deinhardt et al., 2006; Maday et al., 2012; Cheng et al., 2015). In agreement with this model, organelles with increasing levels of acidity are observed from distal to proximal axons (Overly and Hollenbeck, 1996). The controversy surrounding the presence of bone fide lysosomes at the presynapse is compounded by the fact that common markers of lysosomes such as LAMP1 are present on many non-lysosomal compartments (Vukoja et al., 2018). However, it is clear that fusion of either LEs, lysosomes, or vesicles containing lysosome markers, occurs at distal axons and is both calcium- and SNARE-dependent, with both Syt7 acting as the calcium sensor and VAMP7 as the R-SNARE on the LE/lysosome membrane (Arantes and Andrews, 2006).

Evidence has been accumulating that both Syt7 and VAMP7 (and potentially by extension LEs) are integrated in the SV life cycle. VAMP7 is targeted to SVs via an interaction with its longin domain to the adaptor complex 
AP3 (Scheuber et al., 2006). Interestingly, the VAMP7 longin domain interferes with the formation of SNARE complexes with a variety of Q-SNARE partners (Martinez-Arca et al., 2003), providing a potential explanation for why VAMP7 fails to visit the cell surface during action potential stimulation (Hua et al., 2011; Ramirez et al., 2012). However, VAMP7containing vesicles may support spontaneous SV fusion, since increased cell surface trafficking occurs in resting neurons. In support, expression of VAMP7 lacking its longin domain increases spontaneous SV fusion, suggesting that VAMP7 may be required for this event (Hua et al., 2011). Furthermore, modulation of spontaneous SV fusion events by the signaling molecule reelin was abolished on depletion of endogenous VAMP7 (Bal et al., 2013), suggesting that VAMP7-mediated fusion events occur at the presynapse and can be modulated.

Almost all of the proposed presynaptic functions for Syt7 are dependent on its role as a calcium sensor. For example, Syt7 is postulated to be the calcium sensor for store-operated channel entry-mediated presynaptic calcium increases from the endoplasmic reticulum (ER), which augment spontaneous glutamate release (Chanaday et al., 2021). In addition, Syt7 is proposed to replenish the RRP via a calcium-dependent interaction with calmodulin (Liu et al., 2014). Syt7 is also a candidate calcium sensor for asynchronous release, with the extent of this release modulated by the copy number ratio between fast binding, but low affinity calcium sensors such as Syt1 and slower, higher affinity sensors such as Syt7 (Maximov et al., 2008; Bacaj et al., 2013; Weber et al., 2014; Luo et al., 2015; Li et al., 2017).

Syt7 has also been linked to SV endocytosis. Early studies revealed that Syt7 overexpression increased the number of presynaptic endosomes (Virmani et al., 2003), with subsequent studies reporting slowed SV endocytosis in neurons overexpressing the sensor ( $\mathrm{Li}$ et al., 2017). Interestingly, Syt7 knockdown was sufficient to restore normal SV endocytosis kinetics in Syt1 knockdown neurons, again suggesting a functional link between the two calcium sensors. These results suggest that Syt7 might facilitate endosomal recycling pathways such as ADBE. Syt7 trafficking is largely refractory to stimulation (Dean et al., 2012; Weber et al., 2014), in agreement with its predominant plasma membrane localization (Sugita et al., 2001; Maximov et al., 2008; Dean et al., 2012; Li et al., 2017). This atypical localization may explain some of the disparate functions ascribed to this calcium sensor. Recent evidence supports this view, with the plasma membrane localization of Syt7 critical for its control of multiple aspects of the SV life cycle (Vevea et al., 2021). In these studies, targeting Syt7 to either the plasma membrane or lysosome-associated membrane glycoprotein 1 (LAMP1)-positive vesicles, but not SVs, rescued the functional deficits observed in Syt7 knockout neurons. Plasma membrane targeting of Syt7 was dependent on its cleavage via $\gamma$-secretase and palmitoylation (Vevea et al., 2021), directly placing LEs and the endolysosomal system at the regulatory center of SV recycling.

The presence of two of the most abundant LE/lysosomal markers, VAMP7 and Syt7, in the SV pool suggests that lysosome-related organelles are intermingled in the pool of SVs, however, what could be their role? The evidence implicating LEs/lysosomes in regulation of local protein degradation is sparse. For example, LAMP1-containing organelles in distal axons have different acidity from the LAMP1-containing organelles in proximal axons indicating that they might have lower degradative capacity (Overly and Hollenbeck, 1996; Lie et al., 2021). In contrast, the ESCRT machinery is implicated in activity-dependent degradation of a subset of SV proteins via a pathway that requires Rab35 (Sheehan et al., 2016). Furthermore, cathepsins were detected in distal axons in the Drosophila brain and two parallel pathways, a Rab7-independent and a Rab7-dependent pathway were shown to specifically mediate synaptic degradation of SV proteins and membrane proteins, respectively (Jin et al., 2018). One study described a selective localization of the lysosomal protease cathepsin D to GABA-ergic presynapses and implicated it in the control of endocytic trafficking and GABA-ergic neurotransmission (Li et al., 2019). However, an argument against differential distribution of this lysosomal enzyme to inhibitory presynapses is the observation that cathepsin D knockout mice have global deficits in presynaptic ultrastructure (Partanen et al., 2008; Koch S. et al., 2011) and markedly decreased frequency of miniature excitatory postsynaptic currents, mEPSCs (Koch S. et al., 2011). Therefore, cathepsin D-containing lysosome-related organelles are present at both glutamatergic and GABA-ergic synapses and contribute to excitatory and inhibitory neurotransmission.

However, whether there are lysosomes with degradative capacity present at mammalian presynaptic terminals and what their contribution is, if any, to local degradation is currently unknown.

\section{AUTOPHAGY FUNCTION AND SYNAPTIC VESICLE RECYCLING}

Another key axonal retrograde membrane trafficking route, fully integrated in the endolysosomal system, is the autophagy pathway. The generation of autophagosomes in synaptic terminals involves the sequential recruitment and activation of a series of protein complexes, with the main membrane donor being the endoplasmic reticulum [summarized in Kuijpers et al. (2021a), Overhoff et al. (2021)]. Indeed, when autophagy is disrupted via the loss of the key molecule autophagy protein 5 (Atg5), there is increased calcium release from presynaptic ER, resulting in enhanced excitatory neurotransmission (Kuijpers et al., 2021b). Synaptic autophagosome formation appears to be a constitutive process, unlike nutrient starvation-triggered events in non-neuronal cells (Maday and Holzbaur, 2014) and may aid the turnover/degradation of SVs and their cargos (Ravikumar et al., 2010; Maday et al., 2012). Maturation of autophagosomes into autolysosomes involves their fusion with degradative lysosomes and retrograde transport toward the cell body (Itakura et al., 2012; Takáts et al., 2013). Alternatively, they can also fuse with LE to form amphisomes, which perform discrete signaling roles, particularly when transporting growth factor receptors (Villarroel-Campos et al., 2018; Andres-Alonso et al., 2019). As 
outlined above, manipulation of the autophagy pathway results in altered neurotransmission, implicating this pathway as another control point in the SV life cycle. Furthermore, autophagy also requires proteins with defined roles in SV recycling and clathrin-independent endocytosis pathways (Milosevic et al., 2011; Pechstein et al., 2015; Kroll et al., 2019), such as endophilin and synaptojanin-1 (Soukup et al., 2016; Soukup and Verstreken, 2017; Vanhauwaert et al., 2017). In addition, the active zone protein bassoon modulates autophagy via sequestration of the Atg5 (Okerlund et al., 2017). This suggests that both SV recycling and autophagy pathways are intricately linked in terms of both function and molecular requirements.

\section{DISCUSSION}

The question whether SV recycling involves an endosomal intermediate is surprisingly still a matter of debate (Jähne et al., 2015), even when one considers that most, if not all, reported EE, RE, and LE markers are present in the SV pool and with many having direct effects on presynaptic function. Furthermore, the ever-increasing subdivision of functional SV pools described above suggests that the presynapse harbors a collection of functionally diverse organelles with distinct molecular compositions, not all of which engage directly in neurotransmission. This leads to the question, how interdependent are SV recycling and the endolysosomal system, and perhaps more provocatively, are these apparently different processes part of the same cellular continuum? In the section below, we outline a series of hypotheses, supported by the current literature which provide a potentially unifying model for membrane trafficking at the presynapse.

\section{How Homogenous Are Synaptic Vesicles and Are Many Recycling Endosomes/Late Endosomes in Disguise?}

REs are a heterogeneous population of tubulovesicular membrane-bound organelles $\sim 60-100 \mathrm{~nm}$ in diameter (Willingham and Pastan, 1980; Willingham et al., 1984). An argument against a potential link between REs and SVs is the morphological uniformity of SVs that has been observed in multiple studies and attributed to the functioning of specific endocytic mechanisms (Zhang et al., 1998; Shimizu et al., 2003; Koo et al., 2015; Ivanova et al., 2020). However, electron microscopy (EM) studies from ultrathin sections have shown that the size of SVs exists in a range from 25 to $80 \mathrm{~nm}$ (Fox, 1988; Harris and Sultan, 1995). It is not always possible to reconstruct membrane continuity from such ultrathin sections and therefore the length at which SVs extend is difficult to appreciate. Contrary to the prevailing view that SVs have only a spherical shape, studies exist showing that SVs may not be morphologically uniform. Pleomorphic vesicles have been described in early EM studies, mostly as a marker for inhibitory synapses (Uchizono, 1965 and more recently, Koo et al., 2015; Li et al., 2019). With the advent of new technologies (e.g., cryo-EM and electron tomography) there is increasing evidence that tubule-shaped ellipsoidal vesicles are present at both excitatory and inhibitory synapses (Tao et al., 2018). Therefore, similarly to REs, SVs show a degree of morphological heterogeneity, with a diameter that ranges within tens of nanometers.

SVs are also functionally diverse and molecularly heterogeneous. Previous bulk biochemical approaches described the protein composition of a prototypical SV (Takamori et al., 2006; Wilhelm et al., 2014; Wittig et al., 2021). While providing insight into the molecular composition of an average SV, an important caveat of these bulk proteomic studies is that the cellular fractions that were analyzed represent averages of a diverse array of synapses and SVs. The copy number of common SV proteins, such as synaptobrevin2, synaptophysin, and synaptogyrin, in individual SVs shows a significant intervesicle variability, as revealed by single molecular quantification approaches (Mutch et al., 2011). Another important limitation of these early proteomic studies is that they have a bias toward proteins with high abundance, while underrepresented proteins with essential functions, often remain undetected. More recent studies report a longer list of proteins found in isolated synaptosomes, with low abundance proteins (less than 1 copy per SV) being the dominant fraction (Taoufiq et al., 2020). All of this suggests that different proteins are likely differentially distributed to different SV subpopulations. The presence of a multitude of endolysosomal molecules in the total SV pool that exert fine control over different steps of the SV cycle therefore strongly supports the notion that the two systems form a continuum (Figure 1).

The disparity of endolysosomal molecules within the SV pool (Table 1) suggests that some vesicles previously assumed to be SVs may in fact be intermediates of the endolysosomal pathway. In support, SVs are functionally similar to REs, as they are involved in slow, regulated and constitutive recycling of SV cargo to the plasma membrane. Furthermore, a handful of molecular markers characteristic for RE have been implicated in SV function as discussed above. For instance, the Rab35/Arf6 axis directly impacts SV composition and function. Furthermore the RE marker, Rab11 impacts calciumregulated exocytosis of dense core vesicles and SVs and integrates regulated and constitutive exocytosis in neurons and neuroendocrine cells (Khvotchev et al., 2003), while facilitating SV endocytosis modes in central nerve terminals (Kokotos et al., 2018). The only described R-SNARE associated with RE, cellubrevin, is a structural homologue of the most abundant SV R-SNARE, synaptobrevin2 (McMahon et al., 1993). It quantitatively co-isolates with synaptophysin, when expressed in a heterologous system, suggesting that both localize on the same vesicles (McMahon et al., 1993). In further support of the hypothesis that some recycling SVs may be the equivalent of the $\mathrm{RE}$ in the presynaptic terminal, cellubrevin fully rescues synaptic transmission when expressed in synaptobrevin2deficient neurons (Deák et al., 2006).

Similarly, LE/lysosome fusion events may be responsible for a series of functional outputs ascribed to particular SV subpopulations. The mobilization of the resting SV pool is of particular interest, since the LE/lysosome effectors VAMP7 


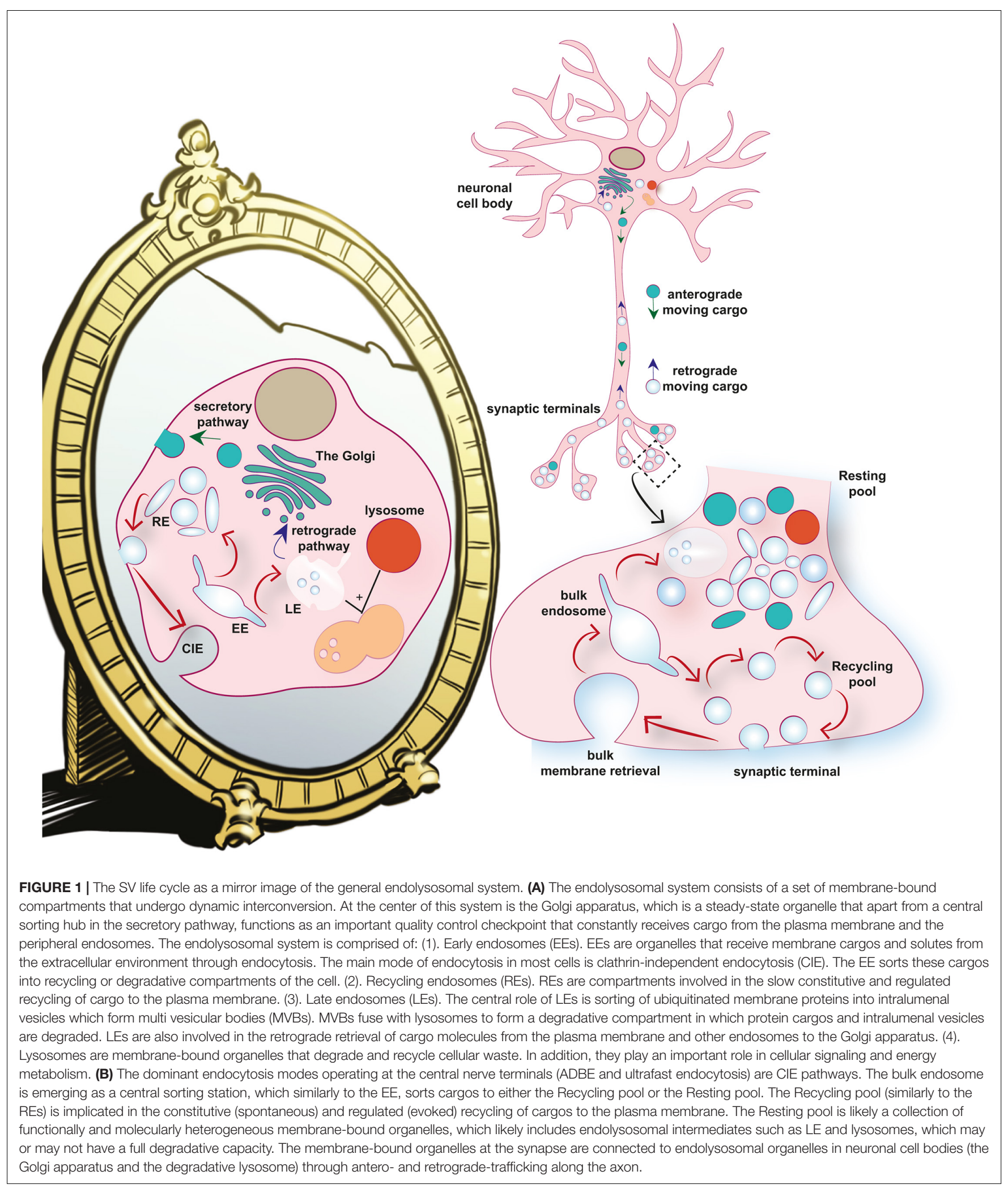

and Syt7 are both represented in this SV pool. For example, the calcium-dependent nature of the VAMP7-dependent fusion events evoked by reelin ( $\mathrm{Bal}$ et al., 2013), is reminiscent of ionophore-evoked lysosome fusion in non-neuronal cells. This may have great relevance, since the plasma membrane deposition of Syt7 impacts a series of SV recycling events (Vevea et al., 
2021), suggesting lysosome fusion is a prerequisite for optimal presynaptic function. However, the reciprocal control of the resting SV pool by the calcium-activated protein phosphatase calcineurin and the protein kinase cyclin-dependent kinase 5 (Kim and Ryan, 2010) appears to operate in a reverse manner for lysosome fusion (Medina et al., 2015; Ishii et al., 2019). Therefore, more work is required to determine the specific molecular nature of the organelles that undergo regulated fusion at the presynapse.

\section{A Reappraisal of the Synaptic Vesicle Pool Nomenclature}

The concept of SV pools was introduced as a model to explain the functional diversity of SVs present in the presynaptic terminal and their distinct contribution to different forms of neurotransmitter release (Alabi and Tsien, 2012). As hypothesized above, the ever-increasing complexity of SV subpopulations that contribute to specific functional fusion or release events suggests a disparate composition of the total SV pool, with potentially direct contributions from different endolysosomal organelles. The SV pool model has proven its utility for describing the plasticity of neurotransmitter release in terms of changes of SV pool sizes (Kim and Ryan, 2010; Rey et al., 2020). However, as with any model, it has its limitations (Neher, 2015). The main limitation is that it remains too deterministic in its original interpretation, and in specific cases, it postulates that distinct pools with specific molecular composition mediate different forms of release (Crawford and Kavalali, 2015). In reality, the dynamic behavior of complex biological systems, such as the SV life cycle, is inherently stochastic. Molecules are randomly distributed to different SV populations and complex regulatory mechanisms guide probabilistic outcomes. Because of this, qualitatively similar functional outcomes may arise from the interactions of different and varied number of molecules, each present on SVs in a small absolute quantity.

The pool model also fails to explain why the resting pool both in vitro and in vivo cannot be released even after extensive periods of synaptic stimulation (Alabi and Tsien, 2012). The reluctant nature of these SVs to participate in activity-dependent recycling suggest that they might be endosomes that have roles other than a direct contribution to neurotransmitter release. For instance, these resting SVs might function as a reservoir of molecules that can be incorporated into the recycling pool on demand (during sorting, as discussed below) to allow plastic changes of SV composition and function (Denker et al., 2011). In addition, part of the resting pool, may in fact be comprised of a series of endolysosomal intermediates primed for transport to neuronal cell bodies and the degradative pathways (Figure 1).

In many cases, the pool model comes short in providing a good correlation between morphology and function. Thus, loss of function of molecules, such as synaptobrevin2 (Deák et al., 2004), munc-13 (Varoqueaux et al., 2002), munc-18 (Verhage et al., 2000), and calcium channels (Held et al., 2020), that strongly reduce or eliminate any forms of neurotransmitter release, does not have any major impact on synaptic ultrastructure and the number of SVs per synaptic terminal. In contrast, the integrity of the SV cluster is compromised when the function of key endosomal sorting proteins is abrogated (Glyvuk et al., 2010; Tagliatti et al., 2016). This implies that the SV pool and its clustering at the synapse are driven by intrinsic programs in the neuron and SV recycling is not essential for maintaining its integrity.

Contrary to the pool model, SV fusion and neurotransmitter release are likely an emerging property of a small subset of the endolysosomes orchestrated in the presynaptic terminal that has been selected through evolution to support the central function of the nervous system, neuronal communication. Indeed, the ultrastructural organization of excitatory presynaptic terminals that developed in complete absence of glutamate release (due to Cre-induced expression of tetanus toxin), was largely preserved, with a normal number of SVs and led to normal refinement of connectivity in the developing brain (Sando et al., 2017; Sigler et al., 2017). Furthermore, the universal excitatory (glutamate, aspartate, and cysteic acid) and inhibitory neurotransmitters (GABA, glycine), are amino acids and the endolysosomal system is a well-established storage site for free amino acids (Russnak et al., 2001; Abu-Remaileh et al., 2017). Some of these intralumenal amino acids are a key element of a central endolysosomal mechanism for nutrient sensing and metabolic control that operates in virtually all cells and organs (Lawrence and Zoncu, 2019). Furthermore, the transport of classical neurotransmitters and neuromodulators into SVs is driven by members of the solute carrier family of transporters (SLC) (Schuldiner et al., 1995; Anne and Gasnier, 2014), that are broadly expressed in various endolysosomal structures and are essential to vital processes within and outside the nervous system (Serrano-Saiz et al., 2020). In addition to their ability to transport amino acids, some of these channels operate as ion channels and regulate the ion gradients and acidification of endosomes (Martineau et al., 2017). The import of neurotransmitters could therefore be considered a by-product of the establishment of these electrochemical gradients, that have additional roles in the functioning of endosomes.

Additional support for the hypothesis that the SV pool is not an autonomous module, operating independently in isolated synaptic terminals, is provided by the existence of a superpool of SVs. Although it is generally accepted that the SV pool and recycling are local, synapse-specific phenomena, overwhelming evidence exists that the pool is not confined to a particular synapse, but spans multiple synapses in a single axon (Staras et al., 2010). Photobleaching and photoactivation experiments have demonstrated that recycling SVs, and synaptic proteins in general, quickly redistribute among neighboring synapses and even between synapses and neuronal cell bodies (Tsuriel et al., 2006; Staras et al., 2010; Ivanova et al., 2015). Thus, the SV pool is shared among many synapses and consists of multiple interconnected organelles that continuously shuttle (in both directions) between axons and neuronal cell bodies. Based on this, a different model emerges, in which the SV pool can be presented as a collection of molecularly heterogeneous endosomes. Owing to the accumulation of specific sets of molecules during the elaborate process of endosomal sorting, a small fraction of these endosomes engages in regulated (evoked) as well as constitutive (spontaneous) release in the confines of 
TABLE 1 | Common endolysosomal proteins present in the SV proteome.

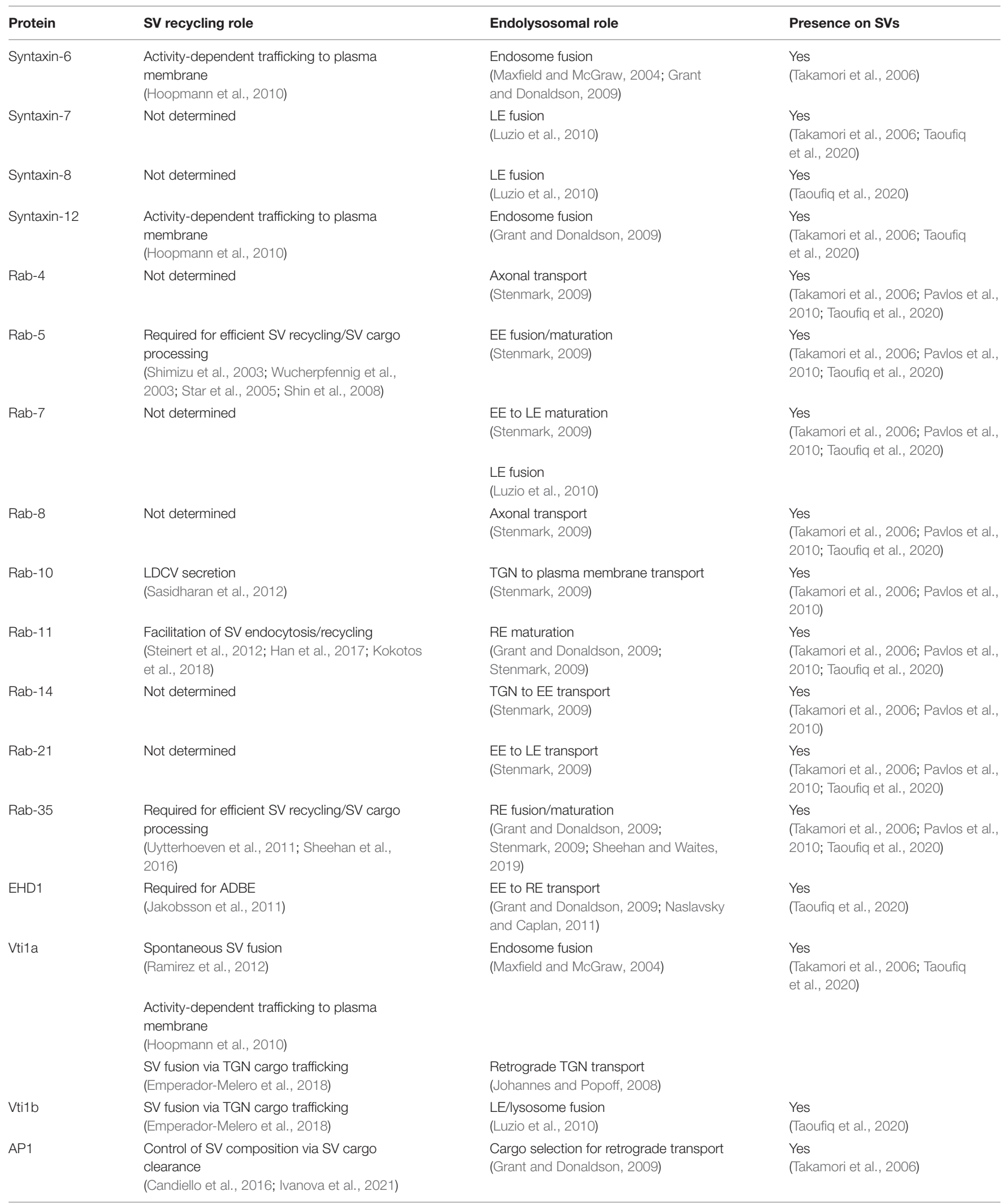

(Continued) 
TABLE 1 | (Continued)

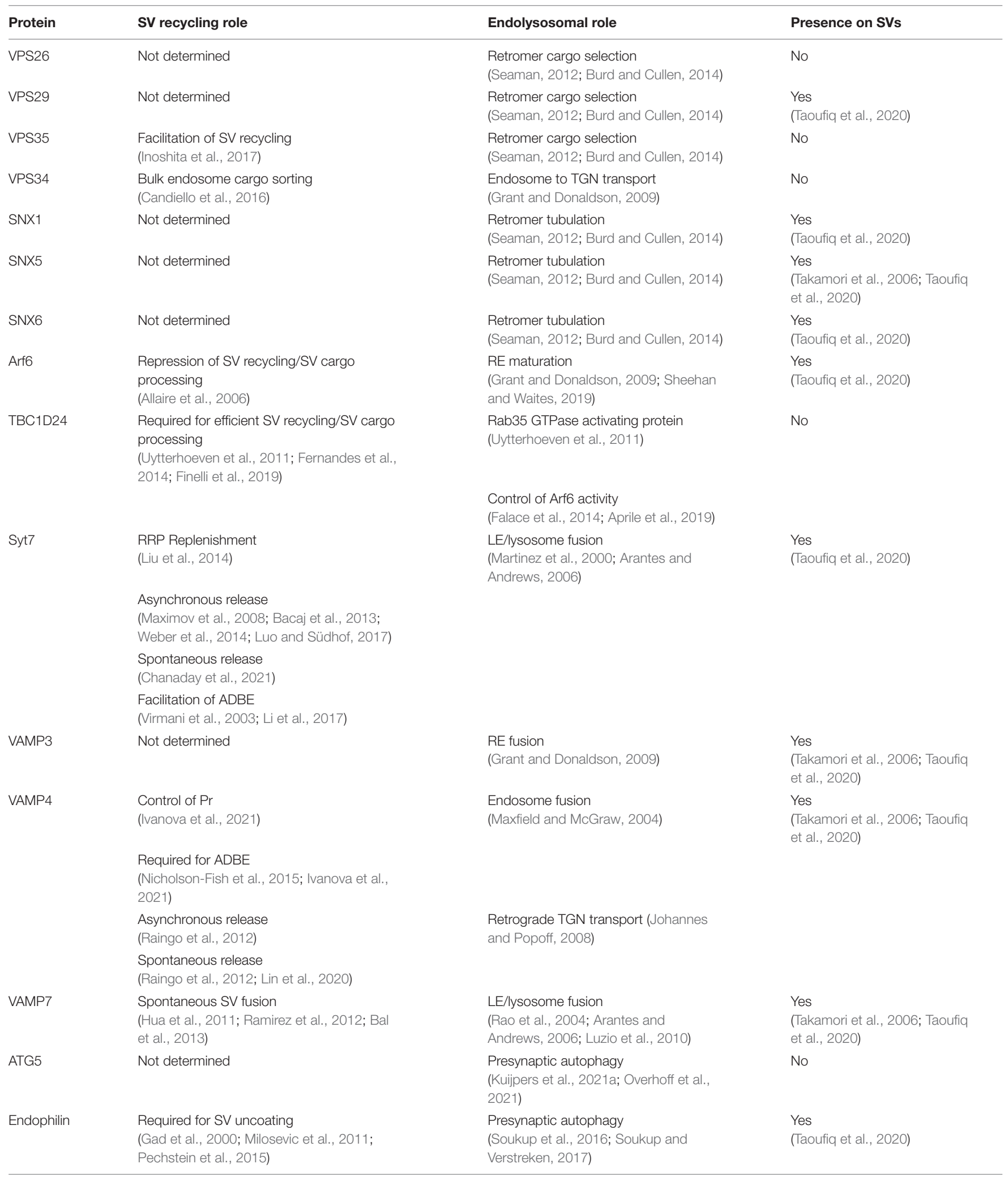


TABLE 1 | (Continued)

\begin{tabular}{|c|c|c|c|}
\hline Protein & SV recycling role & Endolysosomal role & Presence on SVs \\
\hline & $\begin{array}{l}\text { Required for SV endocytosis } \\
\text { (Gad et al., 2000; Sundborger et al., 2011; } \\
\text { Watanabe et al., 2018) }\end{array}$ & & \\
\hline & $\begin{array}{l}\text { Calcium influx and SV recycling } \\
\text { (Kroll et al., 2019; Gowrisankaran et al., 2020) }\end{array}$ & & \\
\hline LAMP1 & Not determined & $\begin{array}{l}\text { Maintenance of lysosome integrity } \\
\text { (Saftig and Klumperman, 2009) }\end{array}$ & $\begin{array}{l}\text { Yes } \\
\text { (Takamori et al., 2006; Taoufiq } \\
\text { et al., 2020) }\end{array}$ \\
\hline
\end{tabular}

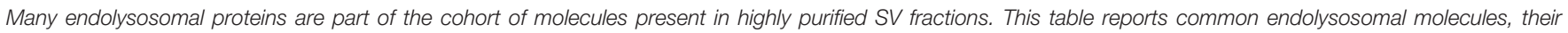
proposed role in the SV life cycle and their presence on purified SVS.

a specific synapse (Kaeser and Regehr, 2014; Chanaday and Kavalali, 2018). However, the SV cycle is nested in a larger cycle that encompasses membrane-bound organelles that reside in both, presynaptic sites and neuronal cell bodies.

\section{Lessons Learned From Studying the Trafficking of the Endosomal R-SNARE VAMP4 at the Presynapse}

As described above, VAMP4 is an endosomal R-SNARE implicated in homo- and heterotypic endosomal fusion which continuously shuttles between endosomes and the TGN in non-neuronal cells. In neurons it is enriched at the TGN as well as in distal axons. In nerve terminals, the majority of VAMP4 is sorted during ADBE to vesicles that are refractory to synaptic stimulation (Nicholson-Fish et al., 2015; Ivanova et al., 2021). Retrograde axonal trafficking of VAMP4 on vesicles that are positive for Rab7 (presumably LEs) mediates its continuous retrieval from nerve terminals and recycles it back to neuronal cell bodies. A small fraction of the VAMP4 pool is present on SVs that undergo activitydependent exocytosis (recycling SVs) and its abundance in the SV pool inversely correlates with SV fusion (Ivanova et al., 2021). Thus, VAMP4 is an example of a protein that shows a wide distribution to different membrane-bound organelles, once again highlighting the interconnectedness of the endolysosomal system and SVs.

Activity-dependent SV endocytosis modes such as ultrafast endocytosis and ADBE are the dominant mechanism for SV cargo and membrane retrieval at central synaptic terminals (Chanaday et al., 2019). Therefore, the great majority of SVs mobilized during synaptic activity recycles through a common endosomal intermediate, the bulk endosome. To mediate efficient neurotransmitter release, recycling SVs must garner a specific set of proteins in a certain stoichiometric ratio. However, a systematic model of the molecular mechanisms underpinning differential protein sorting during SV recycling is currently missing. Di-leucine and tyrosine-based motifs are known to be involved in endolysosomal targeting of proteins (Bonifacino and Traub, 2003), such as with VAMP4, whose cytoplasmic domain possesses a di-leucine motif which mediates its AP1-dependent sorting to endosomes and lysosome-related organelles (Peden et al., 2001). The presence of a di-leucine signal in VAMP4 is likely the underlying reason for its limited localization to recycling SVs and its enrichment on bulk endosomes (Nicholson-Fish et al., 2015).

However, there is no common sorting motif responsible for selective targeting of proteins to the recycling SV pool. This might indicate the existence of distinct sorting mechanisms for each individual SV cargo. An alternative model stipulates that removal of molecules is more important than selective incorporation of proteins for generating of SVs with an optimal complement of proteins for recycling. According to this model, recycling SVs, exactly like REs, are the remnants of bulk endosomes (the equivalent of EE) that persist after cargo sorting to LE. The incorporation of classic endolysosomal proteins, such as VAMP4, in the SV pool makes endolysomal sorting a prerequisite step in the reformation of SVs. Based on the similarity between EEs and synaptic bulk endosomes, it is easy to envisage that following endocytic retrieval, the newly formed bulk endosomes mature to a dynamic sorting compartment by undergoing heterotypic fusion with preexisting vesicles/endolysosomes from the resting SV pool. This hypothesis is supported by in vitro data showing that newly endocytosed SVs undergo homotypic fusion and are capable of fusing with early endosomes isolated from other cell types (Rizzoli et al., 2006). However, despite the increasing level of innovation in the imaging tools that drive rapid advancement in cellular neurobiology, currently there is no in cellulo data supporting endosomal fusion at the presynapse. More than anything else, this indicates the urgent need for developing of sufficiently sensitive techniques that break the diffraction barrier but simultaneously allow real-time visualization of membrane trafficking in the confinements of the conventional chemical synapse.

Despite these currently insurmountable technical limitations, we recently showed (indirectly, through studying VAMP4 trafficking at the presynapse) that intermixing of cargos retrieved through endocytosis with classic endolysosomal cargos, presumably prior to endolysosomal sorting, can introduce molecular heterogeneity in SV composition and drive plasticity of neurotransmitter release (Ivanova et al., 2021). This attunes synaptic transmission to both the history of presynaptic activity, and the functionality status of the quality control mechanisms operating throughout the endolysosomal system. 
More importantly, endolysosomal sorting during SV recycling provides a potential conduit for a constitutive, use-dependent turnover of SV components. In support, blocking the sorting of VAMP4 to LEs, using a dominant negative form of Rab7, increased its synaptic expression and slowed down its synaptic turnover (Ivanova et al., 2021). Interestingly, the same intervention also increased the synaptic expression of synaptophysin, although to a lesser extent. Therefore, it is tempting to speculate that active sorting of classic endolysosomal proteins, such as VAMP4, to LEs may promote passive retrieval of SV cargos that do not necessarily possess sorting determinants for targeting to LEs/lysosomes. This can provide a stochastic, pre-emptive mechanism for removal of SV cargos that have participated in recycling (that has been speculated to exist Truckenbrodt et al., 2018) which continuously rejuvenates the SV proteome and thereby maintains synaptic integrity and function.

\section{Cycling Back to Neuronal Cell Bodies; Potential Impact of Re-trafficking to the Trans-Golgi Network and Somatic Lysosomes on Presynaptic Function, Lessons Learned From Models of Disease}

The rapid redistribution of SV proteins between neighboring synapses (in a matter of minutes; Tsuriel et al., 2006; Staras et al., 2010) and between synapses and neuronal cell bodies (in a matter of hours Tsuriel et al., 2006; Ivanova et al., 2015) observed using various live-imaging approaches, indicates a very rapid axonal turnover of $\mathrm{SV}$ components. However, this is at odds with the very slow metabolic turnover of SV proteins, which ranges from several days to several weeks in vitro and in vivo, respectively (Dorrbaum et al., 2018). This suggests that SV proteins may undergo multiple rounds of trafficking between synapses and neuronal cell bodies before being directed to any of the degradative routes. Although synapses are located at a considerable distance from neuronal cell bodies, owing to the function of motor proteins the communication between them is a very rapid and efficient process (GuedesDias and Holzbaur, 2019). However, why would neurons support such a metabolically-expensive strategy to continuously shuttle vesicles and molecules between distal synapses and neuronal cell bodies?

The TGN, which is a central sorting hub in the secretory pathway, is also emerging as a major protein quality control checkpoint (Briant et al., 2017; Hellerschmied et al., 2019; Sun and Brodsky, 2019). Similarly to the quality control systems operating in the ER, specialized molecular machineries residing in the TGN perform protein surveillance and funnel damaged, misfolded or aggregated proteins into pathways that either attempt repair or sequester and degrade the damaged proteins (typically through lysosomal degradation) (Sun and Brodsky, 2019). Therefore, continuous retrograde trafficking and recycling through the TGN of plasma membrane proteins and proteins that normally localize to other endolysosomal compartments, will allow a periodical reevaluation of their state (Figure 2).

This hypothesis that recycling of synaptic proteins to the TGN is essential for synapse integrity, is strongly supported by the key role of retromer in maintaining synaptic health and its involvement in the progression of neurodegenerative diseases such as Alzheimer's and Parkinson's disease (Small and Petsko, 2015). Multiple genetic studies have linked both Alzheimer's and Parkinson's disease to a number of retromerassociated proteins and enhancement of the retromer function was neuroprotective against the pathology of these slowly progressing neurodegenerative diseases (Vilariño-Güell et al., 2011; Wen et al., 2011; Small and Petsko, 2015; McMillan et al., 2017; Brodin and Shupliakov, 2018). The neuroprotective role of the retromer complex is believed to be coupled to its role in retrieving cargo from the plasma membrane and the endosome back to the TGN. However, whether the retrograde trafficking from synaptic endosomes to the TGN is limited to specific cargos or is a more widespread phenomenon with a major impact on synaptic function, remains an open question.

In the light of this hypothesis, one possible function for presynaptic LEs/lysosomes is sorting of SV cargos during SV recycling and directing them to trafficking pathways that carry them back to the soma where they can be subjected to quality control sampling (at the TGN) and/or degradation by somatic lysosomes. This is supported by the clear functional link between lysosomal function and presynaptic health. Neurodegenerative processes associated with lysosomal dysfunction, as in lysosomal storage diseases (LSD), are usually presynaptically initiated and neurodegeneration in these conditions can be curbed by reestablishing presynaptic function (Sambri et al., 2017). SV exoand endocytosis are severely compromised by lysosomal storage dysfunction. Thus, in several LSD mouse models (Twitcher mice, Niemann-Pick disease type $\mathrm{C} 1$, and Mucopolysaccharidosis type 3A), axonal transport of SV-positive vesicles, SV exo-and endocytosis are critically impaired (Xu et al., 2010; Pressey et al., 2012; Wilkinson et al., 2012; Teixeira et al., 2014; Sambri et al., 2017; Bayó-Puxan et al., 2018). This is associated with reduction or aggregation of $\mathrm{SV}$ proteins and axonal swelling which results in compromised neurotransmission. Some of these deficits can be partly attributed to interference with the function of presynaptic autophagy (and reduced fusion of autophagosomes and lysosomes). However, the severe presynaptic phenotypes in LSD mouse models, strongly suggest that the SV cycle is a loop within a loop, and that it is structurally and functionally integrated in the general endolysosomal system of the neuron. Therefore, deficits at either end of the system will compromise the function of the whole system.

\section{Outlook}

Transitioning from a purely analytic approach to SV recycling to a more systemic one at a molecular level, which recognizes and studies the SV cycle as an integral part of the endomembrane system of the neuron is key for answering outstanding questions in the field by setting the right priorities for future research. Some of these questions are: Which are the cell-biological 


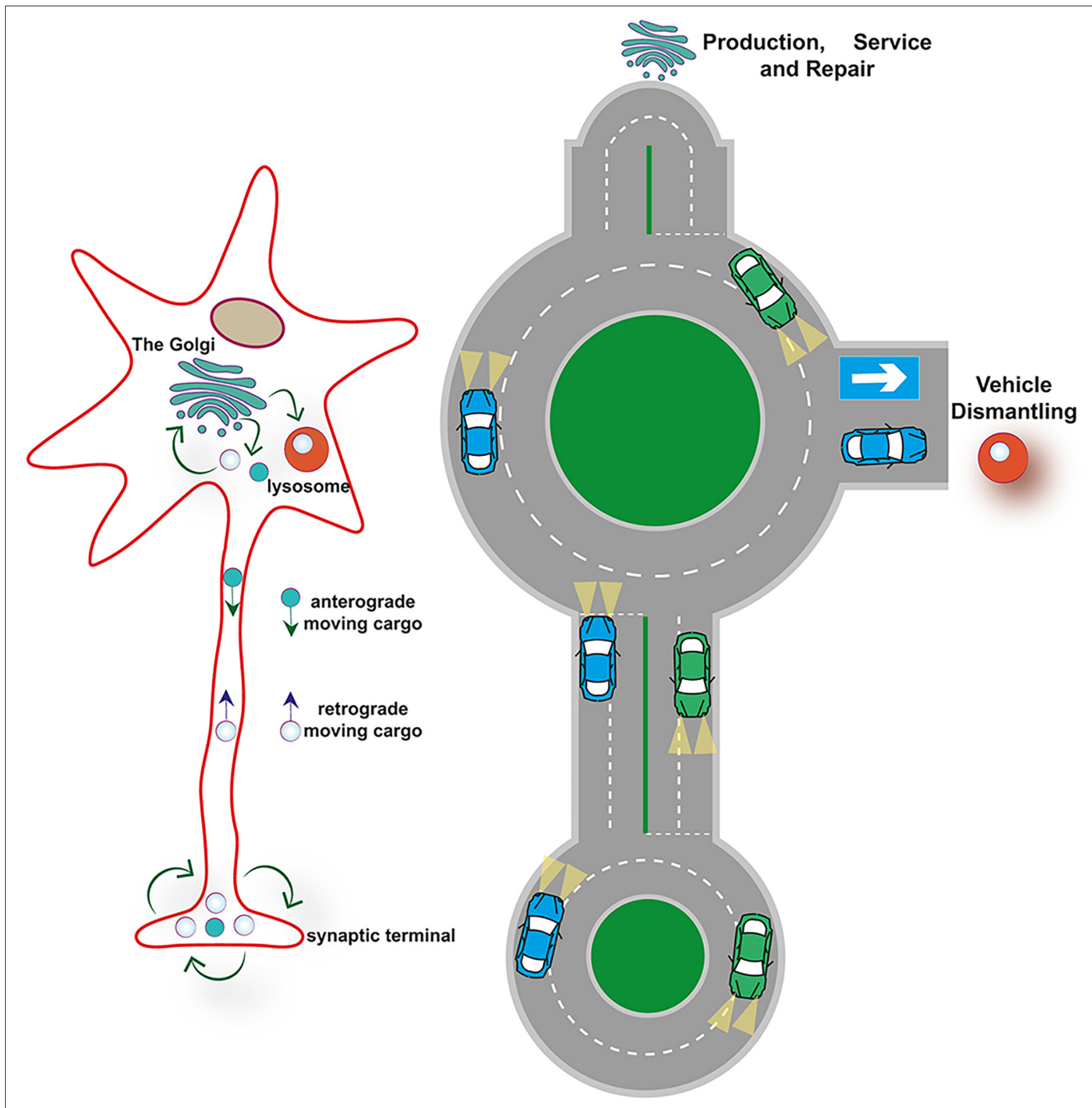

FIGURE 2 | SV recycling is nested in the endolysosomal system. SV recycling is a nested cycle within a larger cycle that encompasses membrane-bound organelles that reside in both, presynaptic sites (the Recycling and Resting pool) and neuronal cell bodies (the Golgi apparatus and degradative lysosomes). The Golgi apparatus performs protein surveillance and funnels cargos to pathways that either repair damage or degrade old and damaged proteins (the lysosome).

mechanisms underlying the assembly and removal of the presynaptic specializations? What drives the use-dependent structural and functional presynaptic plasticity that alters the information coding capacity of the neuron? What mediates the ongoing turnover of SV components which sustains synaptic integrity and function over the lifespan of the neuron? How does previous experience impact these events and is this process tuneable to external signals? Furthermore, multiple neurological disorders ranging from neurodevelopmental autism spectrum disorders and epilepsy to slowly progressing neurodegenerative disorders can be linked to deficits in endolysosomal function and concomitant presynaptic malfunction. To prevent or delay the onset of such disorders and assist in developing targeted therapies in the future, disentangling the systems that regulate these 
complex diseases is key and requires examining the interplay among the underlying factors at a molecular level.

\section{AUTHOR CONTRIBUTIONS}

DI conceived the topic. DI and MC wrote all drafts of the manuscript. Both authors contributed to the article and approved the submitted version.

\section{REFERENCES}

Abu-Remaileh, M., Wyant, G. A., Kim, C., Laqtom, N. N., Abbasi, M., Chan, S. H., et al. (2017). Lysosomal metabolomics reveals V-ATPase- and mTORdependent regulation of amino acid efflux from lysosomes. Science 358, $807-$ 813. doi: 10.1126/science.aan6298

Ackermann, F., Schink, K. O., Bruns, C., Izsvák, Z., Hamra, F. K., Rosenmund, C. et al. (2019). Critical role for Piccolo in synaptic vesicle retrieval. Elife 8:e46629. doi: 10.7554/eLife.46629

Alabi, A. A., and Tsien, R. W. (2012). Synaptic vesicle pools and dynamics. Cold Spring Harb. Perspect. Biol. 4:a013680. doi: 10.1101/cshperspect.a013680

Allaire, P. D., Ritter, B., Thomas, S., Burman, J. L., Denisov, A. Y., LegendreGuillemin, V., et al. (2006). Connecdenn, a novel DENN domain-containing protein of neuronal clathrin-coated vesicles functioning in synaptic vesicle endocytosis. J. Neurosci. 26, 13202-13212. doi: 10.1523/jneurosci.460806.2006

Andres-Alonso, M., Ammar, M. R., Butnaru, I., Gomes, G. M., Acuna Sanhueza, G., Raman, R., et al. (2019). SIPA1L2 controls trafficking and local signaling of TrkB-containing amphisomes at presynaptic terminals. Nat. Commun. 10:5448. doi: 10.1038/s41467-019-13224-Z

Andres-Alonso, M., Kreutz, M. R., and Karpova, A. (2021). Autophagy and the endolysosomal system in presynaptic function. Cell Mol. Life Sci. 78, 2621-2639. doi: 10.1007/s00018-020-03722-5

Anne, C., and Gasnier, B. (2014). Vesicular neurotransmitter transporters: mechanistic aspects. Curr. Top. Membr. 73, 149-174. doi: 10.1016/b978-0-12800223-0.00003-7

Aprile, D., Fruscione, F., Baldassari, S., Fadda, M., Ferrante, D., Falace, A., et al. (2019). TBC1D24 regulates axonal outgrowth and membrane trafficking at the growth cone in rodent and human neurons. Cell Death Differ. 26, 2464-2478. doi: 10.1038/s41418-019-0313-x

Arantes, R. M., and Andrews, N. W. (2006). A role for synaptotagmin VII-regulated exocytosis of lysosomes in neurite outgrowth from primary sympathetic neurons. J. Neurosci. 26, 4630-4637. doi: 10.1523/jneurosci.0009-06.2006

Bacaj, T., Wu, D., Yang, X., Morishita, W., Zhou, P., Xu, W., et al. (2013). Synaptotagmin-1 and synaptotagmin-7 trigger synchronous and asynchronous phases of neurotransmitter release. Neuron 80, 947-959. doi: 10.1016/j.neuron. 2013.10.026

Bal, M., Leitz, J., Reese, A. L., Ramirez, D. M., Durakoglugil, M., Herz, J., et al. (2013). Reelin mobilizes a VAMP7-dependent synaptic vesicle pool and selectively augments spontaneous neurotransmission. Neuron $80,934-946$. doi: 10.1016/j.neuron.2013.08.024

Ballabio, A., and Bonifacino, J. S. (2020). Lysosomes as dynamic regulators of cell and organismal homeostasis. Nat. Rev. Mol. Cell Biol. 21, 101-118. doi: 10.1038/s41580-019-0185-4

Bayó-Puxan, N., Terrasso, A. P., Creyssels, S., Simão, D., Begon-Pescia, C., Lavigne, M., et al. (2018). Lysosomal and network alterations in human mucopolysaccharidosis type VII iPSC-derived neurons. Sci. Rep. 8:16644. doi: 10.1038/s41598-018-34523-3

Bonanomi, D., Fornasiero, E. F., Valdez, G., Halegoua, S., Benfenati, F., Menegon, A., et al. (2008). Identification of a developmentally regulated pathway of membrane retrieval in neuronal growth cones. J. Cell Sci. 121(Pt 22), 37573769. doi: $10.1242 /$ jcs. 033803

Bonifacino, J. S., and Traub, L. M. (2003). Signals for sorting of transmembrane proteins to endosomes and lysosomes. Annu. Rev. Biochem. 72, 395-447. doi: 10.1146/annurev.biochem.72.121801.161800

\section{FUNDING}

Research discussed in this review was funded in part by the Wellcome Trust [Investigator Award to MC (204954/Z/16/Z)].

\section{ACKNOWLEDGMENTS}

We thank Federico De Luca for help with the artwork.

Bonnycastle, K., Davenport, E. C., and Cousin, M. A. (2021). Presynaptic dysfunction in neurodevelopmental disorders: insights from the synaptic vesicle life cycle. J. Neurochem. 157, 179-207. doi: 10.1111/jnc.15035

Braun, A., Pinyol, R., Dahlhaus, R., Koch, D., Fonarev, P., Grant, B. D., et al. (2005). EHD proteins associate with syndapin I and II and such interactions play a crucial role in endosomal recycling. Mol. Biol. Cell 16, 3642-3658. doi: 10.1091/mbc.e05-01-0076

Briant, K., Johnson, N., and Swanton, E. (2017). Transmembrane domain quality control systems operate at the endoplasmic reticulum and Golgi apparatus. PLoS One 12:e0173924. doi: 10.1371/journal.pone.0173924

Brodin, L., and Shupliakov, O. (2018). Retromer in synaptic function and pathology. Front. Synaptic. Neurosci. 10:37. doi: 10.3389/fnsyn.2018.00037

Brunger, A. T., Choi, U. B., Lai, Y., Leitz, J., and Zhou, Q. (2018). Molecular mechanisms of fast neurotransmitter release. Annu. Rev. Biophys. 47, 469-497. doi: 10.1146/annurev-biophys-070816-034117

Burd, C., and Cullen, P. J. (2014). Retromer: a master conductor of endosome sorting. Cold Spring Harb. Perspect. Biol. 6:a016774. doi: 10.1101/cshperspect. a016774

Candiello, E., Kratzke, M., Wenzel, D., Cassel, D., and Schu, P. (2016). AP$1 /$ sigma $1 \mathrm{~A}$ and AP-1/sigma1B adaptor-proteins differentially regulate neuronal early endosome maturation via the Rab5/Vps34-pathway. Sci. Rep. 6:29950. doi: $10.1038 /$ srep29950

Capitani, N., and Baldari, C. T. (2021). F-Actin dynamics in the regulation of endosomal recycling and immune synapse assembly. Front. Cell Dev. Biol. 9:670882. doi: 10.3389/fcell.2021.670882

Chanaday, N. L., and Kavalali, E. T. (2018). Presynaptic origins of distinct modes of neurotransmitter release. Curr. Opin. Neurobiol. 51, 119-126. doi: 10.1016/j. conb.2018.03.005

Chanaday, N. L., Cousin, M. A., Milosevic, I., Watanabe, S., and Morgan, J. R. (2019). The synaptic vesicle cycle revisited: new insights into the modes and mechanisms. J. Neurosci. 39, 8209-8216. doi: 10.1523/JNEUROSCI.1158-19. 2019

Chanaday, N. L., Nosyreva, E., Shin, O. H., Zhang, H., Aklan, I., Atasoy, D., et al. (2021). Presynaptic store-operated $\mathrm{Ca}(2+)$ entry drives excitatory spontaneous neurotransmission and augments endoplasmic reticulum stress. Neuron 109, 1314.e-1332.e. doi: 10.1016/j.neuron.2021.02.023

Cheng, X. T., Zhou, B., Lin, M. Y., Cai, Q., and Sheng, Z. H. (2015). Axonal autophagosomes recruit dynein for retrograde transport through fusion with late endosomes. J. Cell Biol. 209, 377-386. doi: 10.1083/jcb.201412046

Cheung, G., and Cousin, M. A. (2019). Synaptic vesicle generation from activitydependent bulk endosomes requires a dephosphorylation-dependent dynaminsyndapin interaction. J. Neurochem. 151, 570-583. doi: 10.1111/jnc.14862

Clayton, E. L., Anggono, V., Smillie, K. J., Chau, N., Robinson, P. J., and Cousin, M. A. (2009). The phospho-dependent dynamin-syndapin interaction triggers activity-dependent bulk endocytosis of synaptic vesicles. J. Neurosci. 29, 77067717. doi: 10.1523/jneurosci.1976-09.2009

Clayton, E. L., Evans, G. J., and Cousin, M. A. (2008). Bulk synaptic vesicle endocytosis is rapidly triggered during strong stimulation. J. Neurosci. 28, 6627-6632. doi: 10.1523/jneurosci.1445-08.2008

Conner, S. D., and Schmid, S. L. (2003). Regulated portals of entry into the cell. Nature 422, 37-44. doi: 10.1038/nature01451

Cousin, M. A., Malladi, C. S., Tan, T. C., Raymond, C. R., Smillie, K. J., and Robinson, P. J. (2003). Synapsin I-associated phosphatidylinositol 3-kinase mediates synaptic vesicle delivery to the readily releasable pool. J. Biol. Chem. 278, 29065-29071. doi: 10.1074/jbc.M302386200 
Crawford, D. C., and Kavalali, E. T. (2015). Molecular underpinnings of synaptic vesicle pool heterogeneity. Traffic 16, 338-364. doi: 10.1111/tra.12262

Dall'Armi, C., Devereaux, K. A., and Di Paolo, G. (2013). The role of lipids in the control of autophagy. Curr. Biol. 23, R33-R45. doi: 10.1016/j.cub.2012.10.041

Deák, F., Schoch, S., Liu, X., Südhof, T. C., and Kavalali, E. T. (2004). Synaptobrevin is essential for fast synaptic-vesicle endocytosis. Nat. Cell Biol. 6, 1102-1108. doi: $10.1038 /$ ncb 1185

Deák, F., Shin, O. H., Kavalali, E. T., and Südhof, T. C. (2006). Structural determinants of synaptobrevin 2 function in synaptic vesicle fusion. J. Neurosci. 26, 6668-6676. doi: 10.1523/jneurosci.5272-05.2006

Dean, C., Dunning, F. M., Liu, H., Bomba-Warczak, E., Martens, H., Bharat, V., et al. (2012). Axonal and dendritic synaptotagmin isoforms revealed by a pHluorin-syt functional screen. Mol. Biol. Cell 23, 1715-1727. doi: 10.1091/ mbc.E11-08-0707

Deinhardt, K., Salinas, S., Verastegui, C., Watson, R., Worth, D., Hanrahan, S., et al. (2006). Rab5 and Rab7 control endocytic sorting along the axonal retrograde transport pathway. Neuron 52, 293-305. doi: 10.1016/j.neuron.2006. 08.018

Delvendahl, I., Vyleta, N. P., von Gersdorff, H., and Hallermann, S. (2016). Fast, temperature-sensitive and clathrin-independent endocytosis at central synapses. Neuron 90, 492-498. doi: 10.1016/j.neuron.2016.03.013

Denker, A., Kröhnert, K., Bückers, J., Neher, E., and Rizzoli, S. O. (2011). The reserve pool of synaptic vesicles acts as a buffer for proteins involved in synaptic vesicle recycling. Proc. Natl. Acad. Sci. U.S.A. 108, 17183-17188. doi: 10.1073/ pnas. 1112690108

Derivery, E., Sousa, C., Gautier, J. J., Lombard, B., Loew, D., and Gautreau, A. (2009). The Arp2/3 activator WASH controls the fission of endosomes through a large multiprotein complex. Dev. Cell 17, 712-723. doi: 10.1016/j.devcel.2009. 09.010

Dey, S., Banker, G., and Ray, K. (2017). Anterograde transport of rab4-associated vesicles regulates synapse organization in Drosophila. Cell Rep. 18, 2452-2463. doi: 10.1016/j.celrep.2017.02.034

Doherty, G. J., and McMahon, H. T. (2009). Mechanisms of endocytosis. Annu. Rev. Biochem. 78, 857-902. doi: 10.1146/annurev.biochem.78.081307.110540

Dorrbaum, A. R., Kochen, L., Langer, J. D., and Schuman, E. M. (2018). Local and global influences on protein turnover in neurons and glia. Elife 7:e34202. doi: 10.7554/eLife.34202

Emperador-Melero, J., Huson, V., van Weering, J., Bollmann, C., Fischer von Mollard, G., Toonen, R. F., et al. (2018). Vtila/b regulate synaptic vesicle and dense core vesicle secretion via protein sorting at the Golgi. Nat. Commun. 9:3421. doi: 10.1038/s41467-018-05699-z

Falace, A., Buhler, E., Fadda, M., Watrin, F., Lippiello, P., Pallesi-Pocachard, E., et al. (2014). TBC1D24 regulates neuronal migration and maturation through modulation of the ARF6-dependent pathway. Proc. Natl. Acad. Sci. U.S.A. 111, 2337-2342. doi: 10.1073/pnas.1316294111

Fernandes, A. C., Uytterhoeven, V., Kuenen, S., Wang, Y. C., Slabbaert, J. R., Swerts, J., et al. (2014). Reduced synaptic vesicle protein degradation at lysosomes curbs TBC1D24/sky-induced neurodegeneration. J. Cell Biol. 207, 453-462. doi: 10.1083/jcb.201406026

Finelli, M. J., Aprile, D., Castroflorio, E., Jeans, A., Moschetta, M., Chessum, L., et al. (2019). The epilepsy-associated protein TBC1D24 is required for normal development, survival and vesicle trafficking in mammalian neurons. Hum. Mol. Genet. 28, 584-597. doi: 10.1093/hmg/ddy370

Fox, G. Q. (1988). A morphometric analysis of synaptic vesicle distributions. Brain Res. 475, 103-117. doi: 10.1016/0006-8993(88)90203-x

Gad, H., Ringstad, N., Löw, P., Kjaerulff, O., Gustafsson, J., Wenk, M., et al. (2000). Fission and uncoating of synaptic clathrin-coated vesicles are perturbed by disruption of interactions with the SH3 domain of endophilin. Neuron 27, 301-312. doi: 10.1016/s0896-6273(00)00038-6

Gallon, M., and Cullen, P. J. (2015). Retromer and sorting nexins in endosomal sorting. Biochem. Soc. Trans. 43, 33-47. doi: 10.1042/bst20140290

Glyvuk, N., Tsytsyura, Y., Geumann, C., D’Hooge, R., Huve, J., Kratzke, M., et al. (2010). AP-1/sigma1B-adaptin mediates endosomal synaptic vesicle recycling, learning and memory. EMBO J. 29, 1318-1330. doi: 10.1038/emboj. 2010.15

Gokool, S., Tattersall, D., and Seaman, M. N. J. (2007). EHD1 interacts with retromer to stabilize SNX1 tubules and facilitate endosome-to-Golgi retrieval. Traffic 8, 1873-1886. doi: 10.1111/j.1600-0854.2007.00652.x
Goldenring, J. R. (2015). Recycling endosomes. Curr. Opin. Cell Biol. 35, 117-122. doi: 10.1016/j.ceb.2015.04.018

Goto-Silva, L., McShane, M. P., Salinas, S., Kalaidzidis, Y., Schiavo, G., and Zerial, M. (2019). Retrograde transport of Akt by a neuronal Rab5-APPL1 endosome. Sci. Rep. 9:2433. doi: 10.1038/s41598-019-38637-0

Gowrisankaran, S., Houy, S., Del Castillo, J. G. P., Steubler, V., Gelker, M., Kroll, J., et al. (2020). Endophilin-A coordinates priming and fusion of neurosecretory vesicles via intersectin. Nat. Commun. 11:1266. doi: 10.1038/s41467-02014993-8

Granseth, B., Odermatt, B., Royle, S. J., and Lagnado, L. (2006). Clathrin-mediated endocytosis is the dominant mechanism of vesicle retrieval at hippocampal synapses. Neuron 51, 773-786. doi: 10.1016/j.neuron.2006.08.029

Grant, B. D., and Donaldson, J. G. (2009). Pathways and mechanisms of endocytic recycling. Nat. Rev. Mol. Cell Biol. 10, 597-608. doi: 10.1038/nrm2755

Guedes-Dias, P., and Holzbaur, E. L. F. (2019). Axonal transport: driving synaptic function. Science 366:eaaw9997. doi: 10.1126/science.aaw9997

Han, M., Zou, W., Chang, H., Yu, Y., Zhang, H., Li, S., et al. (2017). A Systematic RNAi screen reveals a novel role of a spindle assembly checkpoint protein bugz in synaptic transmission in C. elegans. Front. Mol. Neurosci. 10:141. doi: 10.3389/fnmol.2017.00141

Harris, K. M., and Sultan, P. (1995). Variation in the number, location and size of synaptic vesicles provides an anatomical basis for the nonuniform probability of release at hippocampal CA1 synapses. Neuropharmacology 34, 1387-1395. doi: 10.1016/0028-3908(95)00142-s

He, L., Wu, X. S., Mohan, R., and Wu, L. G. (2006). Two modes of fusion pore opening revealed by cell-attached recordings at a synapse. Nature 444, 102-105. doi: $10.1038 /$ nature 05250

Held, R. G., Liu, C., Ma, K., Ramsey, A. M., Tarr, T. B., De Nola, G., et al. (2020). Synapse and active zone assembly in the absence of presynaptic $\mathrm{Ca}(2+)$ channels and $\mathrm{Ca}(2+)$ entry. Neuron 107:e669. doi: 10.1016/j.neuron.2020.05.032

Hellerschmied, D., Serebrenik, Y. V., Shao, L., Burslem, G. M., and Crews, C. M. (2019). Protein folding state-dependent sorting at the Golgi apparatus. Mol. Biol. Cell 30, 2296-2308. doi: 10.1091/mbc.E19-01-0069

Herzog, E., Nadrigny, F., Silm, K., Biesemann, C., Helling, I., Bersot, T., et al. (2011). In vivo imaging of intersynaptic vesicle exchange using VGLUT1 Venus knock-in mice. J. Neurosci. 31, 15544-15559. doi: 10.1523/jneurosci.2073-11. 2011

Hirata, T., Fujita, M., Nakamura, S., Gotoh, K., Motooka, D., Murakami, Y., et al. (2015). Post-Golgi anterograde transport requires GARP-dependent endosome-to-TGN retrograde transport. Mol. Biol. Cell 26, 3071-3084. doi: 10.1091/mbc.E14-11-1568

Holt, M., Cooke, A., Wu, M. M., and Lagnado, L. (2003). Bulk membrane retrieval in the synaptic terminal of retinal bipolar cells. J. Neurosci. 23, 1329-1339. doi: 10.1523/jneurosci.23-04-01329.2003

Hoopmann, P., Punge, A., Barysch, S. V., Westphal, V., Buckers, J., Opazo, F., et al. (2010). Endosomal sorting of readily releasable synaptic vesicles. Proc. Natl. Acad. Sci. U.S.A. 107, 19055-19060. doi: 10.1073/pnas.1007037107

Howes, M. T., Kirkham, M., Riches, J., Cortese, K., Walser, P. J., Simpson, F., et al. (2010). Clathrin-independent carriers form a high capacity endocytic sorting system at the leading edge of migrating cells. J. Cell Biol. 190, 675-691. doi: $10.1083 /$ jcb.201002119

Hua, Y., Sinha, R., Martineau, M., Kahms, M., and Klingauf, J. (2010). A common origin of synaptic vesicles undergoing evoked and spontaneous fusion. Nat. Neurosci. 13, 1451-1453. doi: 10.1038/nn.2695

Hua, Z., Leal-Ortiz, S., Foss, S. M., Waites, C. L., Garner, C. C., Voglmaier, S. M., et al. (2011). V-SNARE composition distinguishes synaptic vesicle pools. Neuron 71, 474-487. doi: 10.1016/j.neuron.2011.06.010

Hurley, J. H. (2008). ESCRT complexes and the biogenesis of multivesicular bodies. Curr. Opin. Cell Biol. 20, 4-11. doi: 10.1016/j.ceb.2007.12.002

Hurley, J. H. (2015). ESCRTs are everywhere. Embo J. 34, 2398-2407. doi: 10.15252/ embj.201592484

Inoshita, T., Arano, T., Hosaka, Y., Meng, H., Umezaki, Y., Kosugi, S., et al. (2017). Vps35 in cooperation with LRRK2 regulates synaptic vesicle endocytosis through the endosomal pathway in Drosophila. Hum. Mol. Genet. 26, 29332948. doi: $10.1093 / \mathrm{hmg} / \mathrm{ddx} 179$

Ishii, S., Matsuura, A., and Itakura, E. (2019). Identification of a factor controlling lysosomal homeostasis using a novel lysosomal trafficking probe. Sci. Rep. 9:11635. doi: 10.1038/s41598-019-48131-2 
Itakura, E., Kishi-Itakura, C., and Mizushima, N. (2012). The hairpin-type tailanchored SNARE syntaxin 17 targets to autophagosomes for fusion with endosomes/lysosomes. Cell 151, 1256-1269. doi: 10.1016/j.cell.2012.11.001

Ivanova, D., Dirks, A., Montenegro-Venegas, C., Schone, C., Altrock, W. D., Marini, C., et al. (2015). Synaptic activity controls localization and function of CtBP1 via binding to Bassoon and Piccolo. EMBO J. 34, 1056-1077. doi: 10.15252/embj.201488796

Ivanova, D., Dobson, K. L., Gajbhiye, A., Davenport, E. C., Hacker, D., Ultanir, S. K., et al. (2021). Control of synaptic vesicle release probability via VAMP4 targeting to endolysosomes. Sci. Adv. 7:eabf3873. doi: 10.1126/sciadv.abf3873

Ivanova, D., Imig, C., Camacho, M., Reinhold, A., Guhathakurta, D., MontenegroVenegas, C., et al. (2020). CtBP1-Mediated Membrane Fission Contributes to Effective Recycling of Synaptic Vesicles. Cell Rep. 30, 2444-2459.e7. doi: 10.1016/j.celrep.2020.01.079

Jahn, R., and Scheller, R. H. (2006). SNAREs-engines for membrane fusion. Nat. Rev. Mol. Cell Biol. 7, 631-643. doi: 10.1038/nrm2002

Jähne, S., Rizzoli, S. O., and Helm, M. S. (2015). The structure and function of presynaptic endosomes. Exp. Cell Res. 335, 172-179. doi: 10.1016/j.yexcr.2015. 04.017

Jakobsson, J., Ackermann, F., Andersson, F., Larhammar, D., Löw, P., and Brodin, L. (2011). Regulation of synaptic vesicle budding and dynamin function by an EHD ATPase. J. Neurosci. 31, 13972-13980. doi: 10.1523/jneurosci.1289-11. 2011

Jia, D., Gomez, T. S., Billadeau, D. D., and Rosen, M. K. (2012). Multiple repeat elements within the FAM21 tail link the WASH actin regulatory complex to the retromer. Mol. Biol. Cell 23, 2352-2361. doi: 10.1091/mbc.E11-12-1059

Jin, E. J., Kiral, F. R., Ozel, M. N., Burchardt, L. S., Osterland, M., Epstein, D., et al. (2018). Live observation of two parallel membrane degradation pathways at axon terminals. Curr. Biol. 28, 1027.e-1038.e. doi: 10.1016/j.cub.2018.02.032

Joensuu, M., Martínez-Mármol, R., Padmanabhan, P., Glass, N. R., Durisic, N., Pelekanos, M., et al. (2017). Visualizing endocytic recycling and trafficking in live neurons by subdiffractional tracking of internalized molecules. Nat. Protoc. 12, 2590-2622. doi: 10.1038/nprot.2017.116

Johannes, L., and Popoff, V. (2008). Tracing the retrograde route in protein trafficking. Cell 135, 1175-1187. doi: 10.1016/j.cell.2008.12.009

Kaeser, P. S., and Regehr, W. G. (2014). Molecular mechanisms for synchronous, asynchronous, and spontaneous neurotransmitter release. Annu. Rev. Physiol. 76, 333-363. doi: 10.1146/annurev-physiol-021113-170338

Khvotchev, M. V., Ren, M., Takamori, S., Jahn, R., and Südhof, T. C. (2003). Divergent functions of neuronal Rab11b in Ca2+-regulated versus constitutive exocytosis. J. Neurosci. 23, 10531-10539. doi: 10.1523/jneurosci.23-33-10531. 2003

Kim, S. H., and Ryan, T. A. (2010). CDK5 serves as a major control point in neurotransmitter release. Neuron 67, 797-809. doi: 10.1016/j.neuron.2010.08. 003

Klinkert, K., and Echard, A. (2016). Rab35 GTPase: a central regulator of phosphoinositides and f-actin in endocytic recycling and beyond. Traffic 17, 1063-1077. doi: $10.1111 /$ tra. 12422

Klumperman, J., and Raposo, G. (2014). The complex ultrastructure of the endolysosomal system. Cold Spring Harb. Perspect. Biol. 6:a016857. doi: 10. 1101/cshperspect.a016857

Koch, D., Spiwoks-Becker, I., Sabanov, V., Sinning, A., Dugladze, T., Stellmacher, A., et al. (2011). Proper synaptic vesicle formation and neuronal network activity critically rely on syndapin I. Embo J. 30, 4955-4969. doi: 10.1038/emboj. 2011.339

Koch, S., Molchanova, S. M., Wright, A. K., Edwards, A., Cooper, J. D., Taira, T., et al. (2011). Morphologic and functional correlates of synaptic pathology in the cathepsin D knockout mouse model of congenital neuronal ceroid lipofuscinosis. J. Neuropathol. Exp. Neurol. 70, 1089-1096. doi: 10.1097/NEN. 0b013e318238fc28

Kokotos, A. C., and Cousin, M. A. (2015). Synaptic vesicle generation from central nerve terminal endosomes. Traffic 16, 229-240. doi: 10.1111/tra. 12235

Kokotos, A. C., Peltier, J., Davenport, E. C., Trost, M., and Cousin, M. A. (2018). Activity-dependent bulk endocytosis proteome reveals a key presynaptic role for the monomeric GTPase Rab11. Proc. Natl. Acad. Sci. U.S.A. 115, E10177E10186. doi: 10.1073/pnas.1809189115
Kononenko, N. L., and Haucke, V. (2015). Molecular mechanisms of presynaptic membrane retrieval and synaptic vesicle reformation. Neuron 85, 484-496. doi: 10.1016/j.neuron.2014.12.016

Kononenko, N. L., Puchkov, D., Classen, G. A., Walter, A. M., Pechstein, A., Sawade, L., et al. (2014). Clathrin/AP-2 mediate synaptic vesicle reformation from endosome-like vacuoles but are not essential for membrane retrieval at central synapses. Neuron 82, 981-988. doi: 10.1016/j.neuron.2014.05.007

Koo, S. J., Kochlamazashvili, G., Rost, B., Puchkov, D., Gimber, N., Lehmann, M., et al. (2015). Vesicular synaptobrevin/VAMP2 levels guarded by AP180 control efficient neurotransmission. Neuron 88, 330-344. doi: 10.1016/j.neuron.2015. 08.034

Kroll, J., Jaime Tobón, L. M., Vogl, C., Neef, J., Kondratiuk, I., König, M., et al. (2019). Endophilin-A regulates presynaptic $\mathrm{Ca}(2+)$ influx and synaptic vesicle recycling in auditory hair cells. Embo J. 38:116. doi: 10.15252/embj.2018100116

Kuijpers, M., Azarnia Tehran, D., Haucke, V., and Soykan, T. (2021a). The axonal endolysosomal and autophagic systems. J. Neurochem. 158, 589-602. doi: 10. $1111 /$ jnc. 15287

Kuijpers, M., Kochlamazashvili, G., Stumpf, A., Puchkov, D., Swaminathan, A., Lucht, M. T., et al. (2021b). Neuronal autophagy regulates presynaptic neurotransmission by controlling the axonal endoplasmic reticulum. Neuron 109, 299.e-313.e. doi: 10.1016/j.neuron.2020.10.005

Lawrence, R. E., and Zoncu, R. (2019). The lysosome as a cellular centre for signalling, metabolism and quality control. Nat. Cell Biol. 21, 133-142. doi: 10.1038/s41556-018-0244-7

Li, X., and DiFiglia, M. (2012). The recycling endosome and its role in neurological disorders. Prog. Neurobiol. 97, 127-141. doi: 10.1016/j.pneurobio.2011. 10.002

Li, X., Qin, L., Li, Y., Yu, H., Zhang, Z., Tao, C., et al. (2019). Presynaptic endosomal cathepsin d regulates the biogenesis of GABAergic synaptic vesicles. Cell Rep. 28, 1015.e-1028.e. doi: 10.1016/j.celrep.2019.06.006

Li, Y. C., Chanaday, N. L., Xu, W., and Kavalali, E. T. (2017). Synaptotagmin-1and synaptotagmin-7-dependent fusion mechanisms target synaptic vesicles to kinetically distinct endocytic pathways. Neuron 93, 616.e-631.e. doi: 10.1016/j. neuron.2016.12.010

Lie, P. P. Y., Yang, D. S., Stavrides, P., Goulbourne, C. N., Zheng, P., Mohan, P. S., et al. (2021). Post-Golgi carriers, not lysosomes, confer lysosomal properties to pre-degradative organelles in normal and dystrophic axons. Cell Rep. 35:109034. doi: 10.1016/j.celrep.2021.109034

Lin, P. Y., Chanaday, N. L., Horvath, P. M., Ramirez, D. M. O., Monteggia, L. M., and Kavalali, E. T. (2020). VAMP4 maintains a Ca(2+)-sensitive pool of spontaneously recycling synaptic vesicles. J. Neurosci. 40, 5389-5401. doi: 10.1523/JNEUROSCI.2386-19.2020

Liu, H., Bai, H., Hui, E., Yang, L., Evans, C. S., Wang, Z., et al. (2014). Synaptotagmin 7 functions as a Ca2+-sensor for synaptic vesicle replenishment. Elife 3:e01524. doi: 10.7554/eLife.01524

LoGiudice, L., and Matthews, G. (2006). The synaptic vesicle cycle: is kissing overrated? Neuron 51, 676-677. doi: 10.1016/j.neuron.2006.09.004

Lorenzo, D. N., Badea, A., Davis, J., Hostettler, J., He, J., Zhong, G., et al. (2014). A PIK3C3-ankyrin-B-dynactin pathway promotes axonal growth and multiorganelle transport. J. Cell Biol. 207, 735-752. doi: 10.1083/jcb.201407063

Luo, F., and Südhof, T. C. (2017). ). Synaptotagmin-7-mediated asynchronous release boosts high-fidelity synchronous transmission at a central synapse. Neuron 94, 826.e-839.e. doi: 10.1016/j.neuron.2017.04.020

Luo, F., Bacaj, T., and Südhof, T. C. (2015). Synaptotagmin-7 is essential for Ca2+triggered delayed asynchronous release but not for $\mathrm{Ca} 2+$-dependent vesicle priming in retinal ribbon synapses. J. Neurosci. 35, 11024-11033. doi: 10.1523/ jneurosci.0759-15.2015

Luzio, J. P., Gray, S. R., and Bright, N. A. (2010). Endosome-lysosome fusion. Biochem. Soc. Trans. 38, 1413-1416. doi: 10.1042/bst0381413

Luzio, J. P., Pryor, P. R., and Bright, N. A. (2007). Lysosomes: fusion and function. Nat. Rev. Mol. Cell Biol. 8, 622-632. doi: 10.1038/nrm2217

Maday, S., and Holzbaur, E. L. (2014). Autophagosome biogenesis in primary neurons follows an ordered and spatially regulated pathway. Dev. Cell 30, 71-85. doi: 10.1016/j.devcel.2014.06.001

Maday, S., Wallace, K. E., and Holzbaur, E. L. (2012). Autophagosomes initiate distally and mature during transport toward the cell soma in primary neurons. J. Cell Biol. 196, 407-417. doi: 10.1083/jcb.201106120 
Martineau, M., Guzman, R. E., Fahlke, C., and Klingauf, J. (2017). VGLUT1 functions as a glutamate/proton exchanger with chloride channel activity in hippocampal glutamatergic synapses. Nat. Commun. 8:2279. doi: 10.1038/ s41467-017-02367-6

Martinez, I., Chakrabarti, S., Hellevik, T., Morehead, J., Fowler, K., and Andrews, N. W. (2000). Synaptotagmin VII regulates $\mathrm{Ca}(2+)$-dependent exocytosis of lysosomes in fibroblasts. J. Cell Biol. 148, 1141-1149. doi: 10.1083/jcb.148.6. 1141

Martinez-Arca, S., Rudge, R., Vacca, M., Raposo, G., Camonis, J., ProuxGillardeaux, V., et al. (2003). A dual mechanism controlling the localization and function of exocytic v-SNAREs. Proc. Natl. Acad. Sci. U.S.A. 100, 9011-9016. doi: $10.1073 /$ pnas. 1431910100

Maxfield, F. R., and McGraw, T. E. (2004). Endocytic recycling. Nat. Rev. Mol. Cell Biol. 5, 121-132. doi: 10.1038/nrm1315

Maximov, A., Lao, Y., Li, H., Chen, X., Rizo, J., Sørensen, J. B., et al. (2008). Genetic analysis of synaptotagmin-7 function in synaptic vesicle exocytosis. Proc. Natl. Acad. Sci. U.S.A. 105, 3986-3991. doi: 10.1073/pnas.0712372105

McKenzie, J. E., Raisley, B., Zhou, X., Naslavsky, N., Taguchi, T., Caplan, S., et al. (2012). Retromer guides STxB and CD8-M6PR from early to recycling endosomes. EHD1 guides STxB from recycling endosome to Golgi. Traffic 13, 1140-1159. doi: 10.1111/j.1600-0854.2012.01374.x

McMahon, H. T., Ushkaryov, Y. A., Edelmann, L., Link, E., Binz, T., Niemann, H., et al. (1993). Cellubrevin is a ubiquitous tetanus-toxin substrate homologous to a putative synaptic vesicle fusion protein. Nature 364, 346-349. doi: 10.1038/ $364346 \mathrm{a} 0$

McMillan, K. J., Korswagen, H. C., and Cullen, P. J. (2017). The emerging role of retromer in neuroprotection. Curr. Opin. Cell Biol. 47, 72-82. doi: 10.1016/j. ceb.2017.02.004

Medina, D. L., Di Paola, S., Peluso, I., Armani, A., De Stefani, D., Venditti, R., et al. (2015). Lysosomal calcium signalling regulates autophagy through calcineurin and TFEB. Nat. Cell Biol. 17, 288-299. doi: 10.1038/ncb3114

Milosevic, I., Giovedi, S., Lou, X., Raimondi, A., Collesi, C., Shen, H., et al. (2011). Recruitment of endophilin to clathrin-coated pit necks is required for efficient vesicle uncoating after fission. Neuron 72, 587-601. doi: 10.1016/j.neuron.2011. 08.029

Murray, R. Z., Kay, J. G., Sangermani, D. G., and Stow, J. L. (2005). A role for the phagosome in cytokine secretion. Science 310, 1492-1495. doi: 10.1126/science. 1120225

Mutch, S. A., Kensel-Hammes, P., Gadd, J. C., Fujimoto, B. S., Allen, R. W., Schiro, P. G., et al. (2011). Protein quantification at the single vesicle level reveals that a subset of synaptic vesicle proteins are trafficked with high precision. J. Neurosci. 31, 1461-1470. doi: 10.1523/jneurosci.3805-10.2011

Naslavsky, N., and Caplan, S. (2011). EHD proteins: key conductors of endocytic transport. Trends Cell Biol. 21, 122-131. doi: 10.1016/j.tcb.2010.10.003

Naslavsky, N., and Caplan, S. (2018). The enigmatic endosome - sorting the ins and outs of endocytic trafficking. J. Cell Sci. 131:jcs216499. doi: 10.1242/jcs.216499

Neher, E. (2015). Merits and limitations of vesicle pool models in view of heterogeneous populations of synaptic vesicles. Neuron 87, 1131-1142. doi: 10.1016/j.neuron.2015.08.038

Nicholson-Fish, J. C., Cousin, M. A., and Smillie, K. J. (2016). Phosphatidylinositol 3-kinase couples localised calcium influx to activation of Akt in central nerve terminals. Neurochem. Res. 41, 534-543. doi: 10.1007/s11064-015-1663-5

Nicholson-Fish, J. C., Kokotos, A. C., Gillingwater, T. H., Smillie, K. J., and Cousin, M. A. (2015). VAMP4 is an essential cargo molecule for activitydependent bulk endocytosis. Neuron 88, 973-984. doi: 10.1016/j.neuron.2015. 10.043

Okerlund, N. D., Schneider, K., Leal-Ortiz, S., Montenegro-Venegas, C., Kim, S. A., Garner, L. C., et al. (2017). Bassoon controls presynaptic autophagy through Atg5. Neuron 93, 897.e-913.e. doi: 10.1016/j.neuron.2017.01.026

Orlando, M., Schmitz, D., Rosenmund, C., and Herman, M. A. (2019). Calciumindependent exo-endocytosis coupling at small central synapses. Cell Rep. 29, 3767.e-3774.e. doi: 10.1016/j.celrep.2019.11.060

Overhoff, M., De Bruyckere, E., and Kononenko, N. L. (2021). Mechanisms of neuronal survival safeguarded by endocytosis and autophagy. J. Neurochem. 157, 263-296. doi: 10.1111/jnc.15194

Overly, C. C., and Hollenbeck, P. J. (1996). Dynamic organization of endocytic pathways in axons of cultured sympathetic neurons. J. Neurosci. 16, 6056-6064. doi: 10.1523/jneurosci.16-19-06056.1996
Partanen, S., Haapanen, A., Kielar, C., Pontikis, C., Alexander, N., Inkinen, T., et al. (2008). Synaptic changes in the thalamocortical system of cathepsin D-deficient mice: a model of human congenital neuronal ceroid-lipofuscinosis. J. Neuropathol. Exp. Neurol. 67, 16-29. doi: 10.1097/nen.0b013e31815f 3899

Pavlos, N. J., and Jahn, R. (2011). Distinct yet overlapping roles of Rab GTPases on synaptic vesicles. Small GTPases 2, 77-81. doi: 10.4161/sgtp.2.2. 15201

Pavlos, N. J., Grønborg, M., Riedel, D., Chua, J. J., Boyken, J., Kloepper, T. H., et al. (2010). Quantitative analysis of synaptic vesicle Rabs uncovers distinct yet overlapping roles for Rab3a and Rab27b in Ca2+-triggered exocytosis. J. Neurosci. 30, 13441-13453. doi: 10.1523/jneurosci.0907-10.2010

Pechstein, A., Gerth, F., Milosevic, I., Jäpel, M., Eichhorn-Grünig, M., Vorontsova, O., et al. (2015). Vesicle uncoating regulated by SH3-SH3 domain-mediated complex formation between endophilin and intersectin at synapses. EMBO Rep. 16, 232-239. doi: 10.15252/embr.201439260

Peden, A. A., Park, G. Y., and Scheller, R. H. (2001). The Di-leucine motif of vesicleassociated membrane protein 4 is required for its localization and AP-1 binding. J. Biol. Chem. 276, 49183-49187. doi: 10.1074/jbc.M106646200

Piper, R. C., and Katzmann, D. J. (2007). Biogenesis and function of multivesicular bodies. Annu. Rev. Cell Dev. Biol. 23, 519-547. doi: 10.1146/annurev.cellbio.23. 090506.123319

Pressey, S. N., Smith, D. A., Wong, A. M., Platt, F. M., and Cooper, J. D. (2012). Early glial activation, synaptic changes and axonal pathology in the thalamocortical system of Niemann-Pick type C1 mice. Neurobiol. Dis. 45, 1086-1100. doi: 10.1016/j.nbd.2011.12.027

Quan, A., Xue, J., Wielens, J., Smillie, K. J., Anggono, V., Parker, M. W., et al. (2012). Phosphorylation of syndapin I F-BAR domain at two helix-capping motifs regulates membrane tubulation. Proc. Natl. Acad. Sci. U.S.A. 109, 3760-3765. doi: $10.1073 /$ pnas. 1108294109

Raiborg, C., Schink, K. O., and Stenmark, H. (2013). Class III phosphatidylinositol 3-kinase and its catalytic product PtdIns3P in regulation of endocytic membrane traffic. Febs J. 280, 2730-2742. doi: 10.1111/febs.12116

Raingo, J., Khvotchev, M., Liu, P., Darios, F., Li, Y. C., Ramirez, D. M., et al. (2012). VAMP4 directs synaptic vesicles to a pool that selectively maintains asynchronous neurotransmission. Nat. Neurosci. 15, 738-745. doi: 10.1038/nn. 3067

Ramirez, D. M., Khvotchev, M., Trauterman, B., and Kavalali, E. T. (2012). Vtila identifies a vesicle pool that preferentially recycles at rest and maintains spontaneous neurotransmission. Neuron 73, 121-134. doi: 10.1016/j.neuron. 2011.10.034

Rao, S. K., Huynh, C., Proux-Gillardeaux, V., Galli, T., and Andrews, N. W. (2004). Identification of SNAREs involved in synaptotagmin VII-regulated lysosomal exocytosis. J. Biol. Chem. 279, 20471-20479. doi: 10.1074/jbc.M400798200

Ravikumar, B., Sarkar, S., Davies, J. E., Futter, M., Garcia-Arencibia, M., GreenThompson, Z. W., et al. (2010). Regulation of mammalian autophagy in physiology and pathophysiology. Physiol. Rev. 90, 1383-1435. doi: 10.1152/ physrev.00030.2009

Reddy, A., Caler, E. V., and Andrews, N. W. (2001). Plasma membrane repair is mediated by $\mathrm{Ca}(2+)$-regulated exocytosis of lysosomes. Cell 106, 157-169. doi: 10.1016/s0092-8674(01)00421-4

Renard, H. F., and Boucrot, E. (2021). Unconventional endocytic mechanisms. Curr. Opin. Cell Biol. 71, 120-129. doi: 10.1016/j.ceb.2021.03.001

Rey, S., Marra, V., Smith, C., and Staras, K. (2020). Nanoscale remodeling of functional synaptic vesicle pools in hebbian plasticity. Cell Rep. 30, 20062017.e3. doi: 10.1016/j.celrep.2020.01.051

Richards, D. A., Rizzoli, S. O., and Betz, W. J. (2004). Effects of wortmannin and latrunculin A on slow endocytosis at the frog neuromuscular junction. J. Physiol. 557(Pt 1), 77-91. doi: 10.1113/jphysiol.2004.062158

Rink, J., Ghigo, E., Kalaidzidis, Y., and Zerial, M. (2005). Rab conversion as a mechanism of progression from early to late endosomes. Cell 122, 735-749. doi: 10.1016/j.cell.2005.06.043

Rizo, J. (2018). Mechanism of neurotransmitter release coming into focus. Protein Sci. 27, 1364-1391. doi: 10.1002/pro.3445

Rizzoli, S. O., and Betz, W. J. (2002). Effects of 2-(4-morpholinyl)-8-phenyl-4H1-benzopyran-4-one on synaptic vesicle cycling at the frog neuromuscular junction. J. Neurosci. 22, 10680-10689. doi: 10.1523/jneurosci.22-24-10680. 2002 
Rizzoli, S. O., Bethani, I., Zwilling, D., Wenzel, D., Siddiqui, T. J., Brandhorst, D., et al. (2006). Evidence for early endosome-like fusion of recently endocytosed synaptic vesicles. Traffic 7, 1163-1176. doi: 10.1111/j.1600-0854.2006.00466.x

Russnak, R., Konczal, D., and McIntire, S. L. (2001). A family of yeast proteins mediating bidirectional vacuolar amino acid transport. J. Biol. Chem. 276, 23849-23857. doi: 10.1074/jbc.M008028200

Saftig, P., and Klumperman, J. (2009). Lysosome biogenesis and lysosomal membrane proteins: trafficking meets function. Nat. Rev. Mol. Cell Biol. 10, 623-635. doi: 10.1038/nrm2745

Sambri, I., D’Alessio, R., Ezhova, Y., Giuliano, T., Sorrentino, N. C., Cacace, V., et al. (2017). Lysosomal dysfunction disrupts presynaptic maintenance and restoration of presynaptic function prevents neurodegeneration in lysosomal storage diseases. EMBO Mol. Med. 9, 112-132. doi: 10.15252/emmm.201606965

Sando, R., Bushong, E., Zhu, Y., Huang, M., Considine, C., Phan, S., et al. (2017). Assembly of excitatory synapses in the absence of glutamatergic neurotransmission. Neuron 94, 312-313. doi: 10.1016/j.neuron.2017.03.047

Sasidharan, N., Sumakovic, M., Hannemann, M., Hegermann, J., Liewald, J. F., Olendrowitz, C., et al. (2012). RAB-5 and RAB-10 cooperate to regulate neuropeptide release in Caenorhabditis elegans. Proc. Natl. Acad. Sci. U.S.A. 109, 18944-18949. doi: 10.1073/pnas.1203306109

Scheuber, A., Rudge, R., Danglot, L., Raposo, G., Binz, T., Poncer, J. C., et al. (2006). Loss of AP-3 function affects spontaneous and evoked release at hippocampal mossy fiber synapses. Proc. Natl. Acad. Sci. U.S.A. 103, 16562-16567. doi: 10. 1073/pnas.0603511103

Schuldiner, S., Shirvan, A., and Linial, M. (1995). Vesicular neurotransmitter transporters: from bacteria to humans. Physiol. Rev. 75, 369-392. doi: 10.1152/ physrev.1995.75.2.369

Scott, C. C., Vacca, F., and Gruenberg, J. (2014). Endosome maturation, transport and functions. Semin. Cell Dev. Biol. 31, 2-10. doi: 10.1016/j.semcdb.2014.03. 034

Seaman, M. N. (2012). The retromer complex - endosomal protein recycling and beyond. J. Cell Sci. 125(Pt 20), 4693-4702. doi: 10.1242/jcs.103440

Seaman, M. N., McCaffery, J. M., and Emr, S. D. (1998). A membrane coat complex essential for endosome-to-Golgi retrograde transport in yeast. J. Cell Biol. 142, 665-681. doi: 10.1083/jcb.142.3.665

Selak, S., Braun, J. E., and Fritzler, M. J. (2004). Characterization of early endosome antigen 1 in neural tissues. Biochem. Biophys. Res. Commun. 323, 1334-1342. doi: 10.1016/j.bbrc.2004.09.010

Serrano-Saiz, E., Vogt, M. C., Levy, S., Wang, Y., Kaczmarczyk, K. K., Mei, X., et al. (2020). SLC17A6/7/8 vesicular glutamate transporter homologs in nematodes. Genetics 214, 163-178. doi: 10.1534/genetics.119.302855

Sheehan, P., and Waites, C. L. (2019). Coordination of synaptic vesicle trafficking and turnover by the Rab35 signaling network. Small GTPases 10, 54-63. doi: 10.1080/21541248.2016.1270392

Sheehan, P., Zhu, M., Beskow, A., Vollmer, C., and Waites, C. L. (2016). Activitydependent degradation of synaptic vesicle proteins requires Rab35 and the ESCRT pathway. J. Neurosci. 36, 8668-8686. doi: 10.1523/JNEUROSCI.072516.2016

Shimizu, H., Kawamura, S., and Ozaki, K. (2003). An essential role of Rab5 in uniformity of synaptic vesicle size. J. Cell Sci. 116(Pt 17), 3583-3590. doi: $10.1242 /$ jcs.00676

Shin, N., Jeong, H., Kwon, J., Heo, H. Y., Kwon, J. J., Yun, H. J., et al. (2008). LRRK2 regulates synaptic vesicle endocytosis. Exp. Cell Res. 314, 2055-2065. doi: 10.1016/j.yexcr.2008.02.015

Shitara, A., Shibui, T., Okayama, M., Arakawa, T., Mizoguchi, I., Sakakura, Y., et al. (2013). VAMP4 is required to maintain the ribbon structure of the Golgi apparatus. Mol. Cell Biochem. 380, 11-21. doi: 10.1007/s11010-013-1652-4

Sigler, A., Oh, W. C., Imig, C., Altas, B., Kawabe, H., Cooper, B. H., et al. (2017). Formation and maintenance of functional spines in the absence of presynaptic glutamate release. Neuron 94, 304.e-311.e. doi: 10.1016/j.neuron.2017.03.029

Small, S. A., and Petsko, G. A. (2015). Retromer in Alzheimer disease. Parkinson disease and other neurological disorders. Nat. Rev. Neurosci. 16, 126-132. doi: $10.1038 / \mathrm{nrn} 3896$

Soukup, S. F., and Verstreken, P. (2017). EndoA/Endophilin-A creates docking stations for autophagic proteins at synapses. Autophagy 13, 971-972. doi: 10. 1080/15548627.2017.1286440

Soukup, S. F., Kuenen, S., Vanhauwaert, R., Manetsberger, J., Hernández-Díaz, S., Swerts, J., et al. (2016). A LRRK2-dependent endophilinA phosphoswitch is critical for macroautophagy at presynaptic terminals. Neuron $92,829-844$. doi: 10.1016/j.neuron.2016.09.037

Soykan, T., Kaempf, N., Sakaba, T., Vollweiter, D., Goerdeler, F., Puchkov, D., et al. (2017). Synaptic vesicle endocytosis occurs on multiple timescales and is mediated by formin-dependent actin assembly. Neuron 93, 854-856. doi: 10.1016/j.neuron.2017.02.011

Soykan, T., Maritzen, T., and Haucke, V. (2016). Modes and mechanisms of synaptic vesicle recycling. Curr. Opin. Neurobiol. 39, 17-23. doi: 10.1016/j.conb. 2016.03.005

Star, E. N., Newton, A. J., and Murthy, V. N. (2005). Real-time imaging of Rab3a and Rab5a reveals differential roles in presynaptic function. J. Physiol. 569(Pt 1), 103-117. doi: 10.1113/jphysiol.2005.092528

Staras, K., Branco, T., Burden, J. J., Pozo, K., Darcy, K., Marra, V., et al. (2010). A vesicle superpool spans multiple presynaptic terminals in hippocampal neurons. Neuron 66, 37-44. doi: 10.1016/j.neuron.2010.03.020

Steinert, J. R., Campesan, S., Richards, P., Kyriacou, C. P., Forsythe, I. D., and Giorgini, F. (2012). Rab11 rescues synaptic dysfunction and behavioural deficits in a Drosophila model of Huntington's disease. Hum. Mol. Genet. 21, 29122922. doi: $10.1093 / \mathrm{hmg} / \mathrm{dds} 117$

Stenmark, H. (2009). Rab GTPases as coordinators of vesicle traffic. Nat. Rev. Mol. Cell Biol. 10, 513-525. doi: 10.1038/nrm2728

Stevens, C. F., and Williams, J. H. (2000). "Kiss and run" exocytosis at hippocampal synapses. Proc. Natl. Acad. Sci. U.S.A. 97, 12828-12833. doi: 10.1073/pnas. 230438697

Stoorvogel, W., Strous, G. J., Geuze, H. J., Oorschot, V., and Schwartz, A. L. (1991). Late endosomes derive from early endosomes by maturation. Cell 65, 417-427. doi: 10.1016/0092-8674(91)90459-c

Sugita, S., Han, W., Butz, S., Liu, X., Fernández-Chacón, R., Lao, Y., et al. (2001). Synaptotagmin VII as a plasma membrane $\mathrm{Ca}(2+)$ sensor in exocytosis. Neuron 30, 459-473. doi: 10.1016/s0896-6273(01)00290-2

Sun, Z., and Brodsky, J. L. (2019). Protein quality control in the secretory pathway. J. Cell Biol. 218, 3171-3187. doi: 10.1083/jcb.201906047

Sundborger, A., Soderblom, C., Vorontsova, O., Evergren, E., Hinshaw, J. E., and Shupliakov, O. (2011). An endophilin-dynamin complex promotes budding of clathrin-coated vesicles during synaptic vesicle recycling. J. Cell Sci. 124(Pt 1), 133-143. doi: 10.1242/jcs.072686

Tagliatti, E., Fadda, M., Falace, A., Benfenati, F., and Fassio, A. (2016). Arf6 regulates the cycling and the readily releasable pool of synaptic vesicles at hippocampal synapse. Elife 5:10116. doi: 10.7554/eLife.10116

Takamori, S., Holt, M., Stenius, K., Lemke, E. A., Gronborg, M., Riedel, D., et al. (2006). Molecular anatomy of a trafficking organelle. Cell 127, 831-846. doi: 10.1016/j.cell.2006.10.030

Takáts, S., Nagy, P., Varga, Á, Pircs, K., Kárpáti, M., Varga, K., et al. (2013). Autophagosomal syntaxin17-dependent lysosomal degradation maintains neuronal function in Drosophila. J. Cell Biol. 201, 531-539. doi: 10.1083/jcb. 201211160

Tao, C. L., Liu, Y. T., Sun, R., Zhang, B., Qi, L., Shivakoti, S., et al. (2018). Differentiation and characterization of excitatory and inhibitory synapses by cryo-electron tomography and correlative microscopy. J. Neurosci. 38, 14931510. doi: 10.1523/jneurosci.1548-17.2017

Taoufiq, Z., Ninov, M., Villar-Briones, A., Wang, H. Y., Sasaki, T., Roy, M. C., et al. (2020). Hidden proteome of synaptic vesicles in the mammalian brain. Proc. Natl. Acad. Sci. U.S.A. 117, 33586-33596. doi: 10.1073/pnas.20118 70117

Teixeira, C. A., Miranda, C. O., Sousa, V. F., Santos, T. E., Malheiro, A. R., Solomon, M., et al. (2014). Early axonal loss accompanied by impaired endocytosis, abnormal axonal transport, and decreased microtubule stability occur in the model of Krabbe's disease. Neurobiol. Dis. 66, 92-103. doi: 10.1016/j.nbd.2014. 02.012

Tian, Y., Tang, F. L., Sun, X., Wen, L., Mei, L., Tang, B. S., et al. (2015). VPS35deficiency results in an impaired AMPA receptor trafficking and decreased dendritic spine maturation. Mol. Brain 8:70. doi: 10.1186/s13041-015-0156-4

Truckenbrodt, S., Viplav, A., Jahne, S., Vogts, A., Denker, A., Wildhagen, H., et al. (2018). Newly produced synaptic vesicle proteins are preferentially used in synaptic transmission. EMBO J. 37:e98044. doi: 10.15252/embj.201798044

Tsuriel, S., Geva, R., Zamorano, P., Dresbach, T., Boeckers, T., Gundelfinger, E. D., et al. (2006). Local sharing as a predominant determinant of synaptic matrix molecular dynamics. PLoS Biol. 4:e271. doi: 10.1371/journal.pbio.0040271 
Uchizono, K. (1965). Characteristics of excitatory and inhibitory synapses in the central nervous system of the cat. Nature 207, 642-643. doi: 10.1038/207642a0

Uytterhoeven, V., Kuenen, S., Kasprowicz, J., Miskiewicz, K., and Verstreken, P. (2011). Loss of skywalker reveals synaptic endosomes as sorting stations for synaptic vesicle proteins. Cell 145, 117-132. doi: 10.1016/j.cell.2011.02.039

Vanhauwaert, R., Kuenen, S., Masius, R., Bademosi, A., Manetsberger, J., Schoovaerts, N., et al. (2017). The SAC1 domain in synaptojanin is required for autophagosome maturation at presynaptic terminals. Embo J. 36, 1392-1411. doi: $10.15252 / \mathrm{embj} .201695773$

Varoqueaux, F., Sigler, A., Rhee, J. S., Brose, N., Enk, C., Reim, K., et al. (2002). Total arrest of spontaneous and evoked synaptic transmission but normal synaptogenesis in the absence of Munc13-mediated vesicle priming. Proc. Natl. Acad. Sci. U.S.A. 99, 9037-9042. doi: 10.1073/pnas.122623799

Vazquez-Sanchez, S., Bobeldijk, S., Dekker, M. P., van Keimpema, L., and van Weering, J. R. T. (2018). VPS35 depletion does not impair presynaptic structure and function. Sci. Rep. 8:2996. doi: 10.1038/s41598-018-20448-4

Verhage, M., Maia, A. S., Plomp, J. J., Brussaard, A. B., Heeroma, J. H., Vermeer, H., et al. (2000). Synaptic assembly of the brain in the absence of neurotransmitter secretion. Science 287, 864-869. doi: 10.1126/science.287.5454.864

Vevea, J. D., Kusick, G. F., Courtney, K. C., Chen, E., Watanabe, S., and Chapman, E. R. (2021). Synaptotagmin 7 is targeted to the axonal plasma membrane through $\gamma$-secretase processing to promote synaptic vesicle docking in mouse hippocampal neurons. Elife 10:e67261. doi: 10.7554/eLife.67261

Vietri, M., Radulovic, M., and Stenmark, H. (2020). The many functions of ESCRTs. Nat. Rev. Mol. Cell Biol. 21, 25-42. doi: 10.1038/s41580-019-0177-4

Vilariño-Güell, C., Wider, C., Ross, O. A., Dachsel, J. C., Kachergus, J. M., Lincoln, S. J., et al. (2011). VPS35 mutations in Parkinson disease. Am. J. Hum. Genet. 89, 162-167. doi: 10.1016/j.ajhg.2011.06.001

Villarroel-Campos, D., Schiavo, G., and Lazo, O. M. (2018). The many disguises of the signalling endosome. FEBS Lett. 592, 3615-3632. doi: 10.1002/1873-3468. 13235

Virmani, T., Han, W., Liu, X., Südhof, T. C., and Kavalali, E. T. (2003). Synaptotagmin 7 splice variants differentially regulate synaptic vesicle recycling. Embo J. 22, 5347-5357. doi: 10.1093/emboj/cdg514

Vukoja, A., Rey, U., Petzoldt, A. G., Ott, C., Vollweiter, D., Quentin, C., et al. (2018). Presynaptic biogenesis requires axonal transport of lysosome-related vesicles. Neuron 99, 1216.e-1232.e. doi: 10.1016/j.neuron.2018.08.004

Watanabe, S., Mamer, L. E., Raychaudhuri, S., Luvsanjav, D., Eisen, J., Trimbuch, T., et al. (2018). Synaptojanin and endophilin mediate neck formation during ultrafast endocytosis. Neuron 98, 1184.e-1197.e. doi: 10.1016/j.neuron.2018.06. 005

Watanabe, S., Rost, B. R., Camacho-Perez, M., Davis, M. W., Sohl-Kielczynski, B., Rosenmund, C., et al. (2013). Ultrafast endocytosis at mouse hippocampal synapses. Nature 504, 242-247. doi: 10.1038/nature12809

Watanabe, S., Trimbuch, T., Camacho-Perez, M., Rost, B. R., Brokowski, B., Sohl-Kielczynski, B., et al. (2014). Clathrin regenerates synaptic vesicles from endosomes. Nature 515, 228-233. doi: 10.1038/nature13846

Weber, J. P., Toft-Bertelsen, T. L., Mohrmann, R., Delgado-Martinez, I., and Sørensen, J. B. (2014). Synaptotagmin-7 is an asynchronous calcium sensor for synaptic transmission in neurons expressing SNAP-23. PLoS One 9:e114033. doi: 10.1371/journal.pone. 0114033

Wei, S., Xu, Y., Shi, H., Wong, S. H., Han, W., Talbot, K., et al. (2010). EHD1 is a synaptic protein that modulates exocytosis through binding to snapin. Mol. Cell Neurosci. 45, 418-429. doi: 10.1016/j.mcn.2010.07.014

Wen, L., Tang, F. L., Hong, Y., Luo, S. W., Wang, C. L., He, W., et al. (2011). VPS35 haploinsufficiency increases Alzheimer's disease neuropathology. J. Cell Biol. 195, 765-779. doi: 10.1083/jcb.201105109

White, J. A. II, Krzystek, T. J., Hoffmar-Glennon, H., Thant, C., Zimmerman, K., Iacobucci, G., et al. (2020). Excess Rab4 rescues synaptic and behavioral dysfunction caused by defective HTT-Rab4 axonal transport in Huntington's disease. Acta Neuropathol. Commun. 8:97. doi: 10.1186/s40478-020-00964-z

Wilhelm, B. G., Mandad, S., Truckenbrodt, S., Krohnert, K., Schafer, C., Rammner, B., et al. (2014). Composition of isolated synaptic boutons reveals the amounts of vesicle trafficking proteins. Science 344, 1023-1028. doi: 10.1126/science. 1252884
Wilkinson, F. L., Holley, R. J., Langford-Smith, K. J., Badrinath, S., Liao, A., Langford-Smith, A., et al. (2012). Neuropathology in mouse models of mucopolysaccharidosis type I. IIIA and IIIB. PLoS One 7:e35787. doi: 10.1371/ journal.pone. 0035787

Willingham, M. C., and Pastan, I. (1980). The receptosome: an intermediate organelle of receptor mediated endocytosis in cultured fibroblasts. Cell 21, 67-77. doi: 10.1016/0092-8674(80)90115-4

Willingham, M. C., Hanover, J. A., Dickson, R. B., and Pastan, I. (1984). Morphologic characterization of the pathway of transferrin endocytosis and recycling in human KB cells. Proc. Natl. Acad. Sci. U.S.A. 81, 175-179. doi: 10.1073/pnas.81.1.175

Wittig, S., Ganzella, M., Barth, M., Kostmann, S., Riedel, D., Pérez-Lara, Á, et al. (2021). Cross-linking mass spectrometry uncovers protein interactions and functional assemblies in synaptic vesicle membranes. Nat. Commun. 12:858. doi: $10.1038 / \mathrm{s} 41467-021-21102-\mathrm{w}$

Wollert, T., and Hurley, J. H. (2010). Molecular mechanism of multivesicular body biogenesis by ESCRT complexes. Nature 464, 864-869. doi: 10.1038/ nature 08849

Wu, L. G., Hamid, E., Shin, W., and Chiang, H. C. (2014). Exocytosis and endocytosis: modes, functions, and coupling mechanisms. Annu. Rev. Physiol. 76, 301-331. doi: 10.1146/annurev-physiol-021113-170305

Wucherpfennig, T., Wilsch-Bräuninger, M., and González-Gaitán, M. (2003). Role of Drosophila Rab5 during endosomal trafficking at the synapse and evoked neurotransmitter release. J. Cell Biol. 161, 609-624. doi: 10.1083/jcb.2002 11087

Xu, S., Zhou, S., Xia, D., Xia, J., Chen, G., Duan, S., et al. (2010). Defects of synaptic vesicle turnover at excitatory and inhibitory synapses in Niemann-Pick C1deficient neurons. Neuroscience 167, 608-620. doi: 10.1016/j.neuroscience.2010. 02.033

Yang, C., and Wang, X. (2021). Lysosome biogenesis: regulation and functions. J. Cell Biol. 220:e202102001. doi: 10.1083/jcb.202102001

Zhang, B., Koh, Y. H., Beckstead, R. B., Budnik, V., Ganetzky, B., and Bellen, H. J. (1998). Synaptic vesicle size and number are regulated by a clathrin adaptor protein required for endocytosis. Neuron 21, 1465-1475. doi: 10.1016/s08966273(00)80664-9

Zhang, Q., Li, Y., and Tsien, R. W. (2009). The dynamic control of kiss-and-run and vesicular reuse probed with single nanoparticles. Science 323, 1448-1453. doi: 10.1126/science.1167373

Zhang, X. M., François, U., Silm, K., Angelo, M. F., Fernandez-Busch, M. V., Maged, M., et al. (2019). A proline-rich motif on VGLUT1 reduces synaptic vesicle super-pool and spontaneous release frequency. Elife 8:e50401. doi: 10. 7554/eLife.50401

Zhen, Y., Radulovic, M., Vietri, M., and Stenmark, H. (2021). Sealing holes in cellular membranes. Embo J. 40:e106922. doi: 10.15252/embj.2020106922

Zhou, C., Li, C., Li, D., Wang, Y., Shao, W., You, Y., et al. (2013). BIG1, a brefeldin A-inhibited guanine nucleotide-exchange protein regulates neurite development via PI3K-AKT and ERK signaling pathways. Neuroscience 254, 361-368. doi: 10.1016/j.neuroscience.2013.09.045

Conflict of Interest: The authors declare that the research was conducted in the absence of any commercial or financial relationships that could be construed as a potential conflict of interest.

Publisher's Note: All claims expressed in this article are solely those of the authors and do not necessarily represent those of their affiliated organizations, or those of the publisher, the editors and the reviewers. Any product that may be evaluated in this article, or claim that may be made by its manufacturer, is not guaranteed or endorsed by the publisher.

Copyright (C) 2022 Ivanova and Cousin. This is an open-access article distributed under the terms of the Creative Commons Attribution License (CC BY). The use, distribution or reproduction in other forums is permitted, provided the original author(s) and the copyright owner(s) are credited and that the original publication in this journal is cited, in accordance with accepted academic practice. No use, distribution or reproduction is permitted which does not comply with these terms. 